\title{
Chronic Cognitive Dysfunction after Traumatic Brain Injury Is Improved with a Phosphodiesterase 4B Inhibitor
}

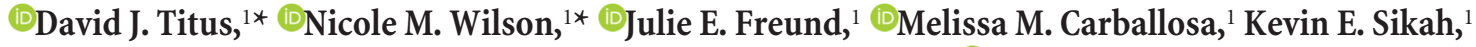 \\ Concepcion Furones, ${ }^{1}$ W. Dalton Dietrich, ${ }^{1}$ Mark E. Gurney, ${ }^{2}$ and ${ }^{\circledR C}$ Coleen M. Atkins ${ }^{1}$ \\ ${ }^{1}$ The Miami Project to Cure Paralysis, Department of Neurological Surgery, University of Miami Miller School of Medicine, Miami, Florida 33136, and \\ 2Tetra Discovery Partners, Grand Rapids, Michigan 49503
}

\begin{abstract}
Learning and memory impairments are common in traumatic brain injury (TBI) survivors. However, there are no effective treatments to improve TBI-induced learning and memory impairments. TBI results in decreased cAMP signaling and reduced cAMP-response-element binding protein (CREB) activation, a critical pathway involved in learning and memory. TBI also acutely upregulates phosphodiesterase 4B2 (PDE4B2), which terminates cAMP signaling by hydrolyzing cAMP. We hypothesized that a subtype-selective PDE4B inhibitor could reverse the learning deficits induced by TBI. To test this hypothesis, adult male Sprague-Dawley rats received sham surgery or moderate parasagittal fluid-percussion brain injury. At 3 months postsurgery, animals were administered a selective PDE4B inhibitor or vehicle before cue and contextual fear conditioning, water maze training and a spatial working memory task. Treatment with the PDE4B inhibitor significantly reversed the TBI-induced deficits in cue and contextual fear conditioning and water maze retention. To further understand the underlying mechanisms of these memory impairments, we examined hippocampal long-term potentiation (LTP). TBI resulted in a significant reduction in basal synaptic transmission and impaired expression of LTP. Treatment with the PDE4B inhibitor significantly reduced the deficits in basal synaptic transmission and rescued LTP expression. The PDE4B inhibitor reduced tumor necrosis factor- $\alpha$ levels and increased phosphorylated CREB levels after TBI, suggesting that this drug inhibited molecular pathways in the brain known to be regulated by PDE4B. These results suggest that a subtype-selective PDE4B inhibitor is a potential therapeutic to reverse chronic learning and memory dysfunction and deficits in hippocampal synaptic plasticity following TBI.
\end{abstract}

Key words: cAMP; cognition; learning; long-term potentiation; phosphodiesterase; traumatic brain injury

Significance Statement

Currently, there are an estimated 3.2-5.3 million individuals living with disabilities from traumatic brain injury (TBI) in the United States, and 8 of 10 of these individuals report cognitive disabilities (Thurman et al., 1999; Lew et al., 2006; Zaloshnja et al., 2008). One of the molecular mechanisms associated with chronic cognitive disabilities is impaired cAMP signaling in the hippocampus. In this study, we report that a selective phosphodiesterase $4 \mathrm{~B}(\mathrm{PDE} 4 \mathrm{~B})$ inhibitor reduces chronic cognitive deficits after TBI and rescues deficits in hippocampal long-term potentiation. These results suggest that PDE4B inhibition has the potential to improve learning and memory ability and overall functioning for people living with TBI.

\section{Introduction}

Traumatic brain injury (TBI) is a serious clinical problem affecting $\sim 1.7$ million people in the United States each year at a cost of $\$ 56$ billion annually (Faul et al., 2010). Currently, it is estimated there are $>3.2-5.3$ million individuals living with TBI in the

Received Aug. 26, 2015; revised May 20, 2016; accepted May 25, 2016.

Author contributions: D.J.T., N.M.W., J.E.F., M.M.C., C.F., W.D.D., M.E.G., and C.M.A. designed research; D.J.T., N.M.W., J.E.F., M.M.C., K.E.S., C.F., and C.M.A. performed research; M.E.G. contributed unpublished reagents/analytic tools; D.J.T., N.M.W., J.E.F., M.M.C., K.E.S., W.D.D., M.E.G., and C.M.A. analyzed data; D.J.T., N.M.W., J.E.F., M.M.C., K.E.S., W.D.D., M.E.G., and C.M.A. wrote the paper.

This work was supported by the National Institutes of Health/National Institute of Neurological Disorders and Stroke R01 NS069721 to C.M.A., R01 NS056072 to C.M.A. and W.D.D., F31 NS089351 to N.M.W., and The Miami Project to Cure Paralysis. M.E.G. acknowledges support by the National Institutes of Health/National Institute of Mental Health R44 MH091791. We thank Jonathan Mendoza, Rosmery Santos, and David Sequeira for technical support, and Dr Xuesheng Mo for synthesis of A33.
United States and as many as 8 of 10 report cognitive disabilities (Thurman et al., 1999; Lew et al., 2006; Zaloshnja et al., 2008). The high prevalence of cognitive disabilities is due, in part, to the vulnerability of the hippocampus, which exhibits bilateral atrophy years after the initial trauma even when not directly injured

${ }^{*}$ D.J.T and N.M.W. contributed equally to this work.

N.M.W., J.E.F., M.M.C., K.E.S., and C.F. declare no competing financial interests. D.J.T., W.D.D., M.E.G., and C.M.A. are co-inventors on USPT0 8,865,723 which claims therapeutic use of PDE4B inhibitors for treating brain injury. Tetra Discovery Partners (M.E.G.) is the owner of this patent. D.J.T., W.D.D., and C.M.A. do not have equity stakes in the company and do not stand to receive royalties.

Correspondence should be addressed to Dr. Coleen M. Atkins, Department of Neurological Surgery, University of Miami Miller School of Medicine, 1095 Northwest 14 Terrace, Miami, FL 33136. E-mail: catkins@med.miami.edu.

DOI:10.1523/JNEUROSCI.3212-15.2016

Copyright $\odot 2016$ the authors $\quad 0270-6474 / 16 / 367095-14 \$ 15.00 / 0$ 
(Bigler et al., 2002; Serra-Grabulosa et al., 2005). Although a significant amount of experimental work has clarified the pathophysiology of TBI, limited success has been obtained in translating therapies to the patient (McConeghy et al., 2012). Thus, there is a continued need to investigate the cellular and molecular targets important in improving outcome in people living with TBI.

TBI significantly impairs cAMP signaling and results in hippocampal synaptic plasticity deficits that translate into poor functional outcome (Atkins et al., 2007; Titus et al., 2013b). In previous studies, we discovered that this decrease in cAMP is associated with an acute upregulation of an enzyme that degrades cAMP, phosphodiesterase 4 (PDE4; Oliva et al., 2012; Wilson et al., 2016). Inhibition of PDE4 by rolipram restores cAMP levels and increases cAMP-response element-binding protein (CREB) phosphorylation after contextual fear conditioning in braininjured animals (Titus et al., 2013b). Pan-PDE4 inhibition by rolipram also significantly improves hippocampal long-term potentiation (LTP) and learning after TBI (Titus et al., 2013a,b). However, rolipram results in nausea and emetic side effects that preclude clinical development (Robichaud et al., 2001). In the context of TBI, postinjury rolipram treatment in the acute recovery period also results in detrimental vascular perturbations (Atkins et al., 2012, 2013). To translate a PDE4 inhibitor to the chronic TBI patient, developing a more selective PDE4 inhibitor that avoids side-effects associated with pan-PDE4 inhibition will more likely achieve clinical success.

There are four PDE4 subfamilies; each encoded by a separate gene (A-D; Houslay et al., 2005). Most PDE4 inhibitors described to date, including rolipram and the FDA-approved roflumilast, inhibit all four subfamilies, although recently PDE4B selective inhibitors have been reported (Naganuma et al., 2009; Press and Banner, 2009; Fox et al., 2014). Studies with genetically modified mice have shown that the PDE4 genes subserve different functions in the brain. PDE4A is involved in anxiety, PDE4B regulates inflammation and alters anxiety levels, PDE4C is not a major isoform in the brain or immune system and PDE4D is involved in memory formation, depression, and adult neurogenesis (Jin et al., 2005; Zhang et al., 2008; Li et al., 2011; Hansen et al., 2014; McGirr et al., 2016).

Recently, the crystal structures of PDE4B and PDE4D have been exploited to develop subtype-selective PDE4 inhibitors (Burgin et al., 2010; Fox et al., 2014). The PDE4B selective inhibitor A33, 2(4-\{[2-(5-chlorothiophen-2-yl)-5-ethyl-6-methylpyrimidin-4yl] amino phenyl)acetic acid (Naganuma et al., 2009), has an $\mathrm{IC}_{50}$ of 32 nM against PDE4B1, is 49-fold more selective for PDE4B versus PDE4D and does not appreciably inhibit any other PDEs (Fox et al., 2014). In comparison, rolipram has an $\mathrm{IC}_{50}$ of $225 \mathrm{~nm}$ toward PDE4B and 288 nM toward PDE4D (Burgin et al., 2010). A33 engages a C-terminal regulatory domain termed CR3 in contrast to rolipram, which engages the $\mathrm{N}$-terminal upstream conserved region 2 regulatory domain (Burgin et al., 2010; Fox et al., 2014). In the present study, we characterized the hippocampal-dependent learning and synaptic plasticity deficits that occur in the chronic recovery phase of TBI. We report that the PDE4B inhibitor A33 reduces learning and memory impairments and rescues expression of hippocampal LTP after TBI.

\section{Materials and Methods}

Materials. Compound A33 (2-(4-\{[2-(5-chlorothiophen-2-yl)-5-ethyl6-methylpyrimidin-4-yl]amino\} phenyl)acetic acid; CAS 915082-52-9) was synthesized as described previously (Naganuma et al., 2009). Inhibitory potency against human PDE4B3 was assayed as previously described (Fox et al., 2014).
Table 1. Physiological parameters

\begin{tabular}{llll}
\hline Parameter & Treatment & At surgery & At perfusion \\
\hline Weight, gm & Sham + vehicle & $393.0 \pm 21.0$ & $600.0 \pm 18.2$ \\
& Sham + A33 & $371.0 \pm 21.7$ & $636.0 \pm 33.1$ \\
& TBI + vehicle & $379.2 \pm 12.1$ & $612.9 \pm 14.0$ \\
& TBI + A33 & $382.4 \pm 11.5$ & $655.2 \pm 22.6$ \\
ATM & TBI + vehicle & $1.98 \pm 0.01$ & \\
& TBI + A33 & $2.02 \pm 0.03$ & \\
\hline
\end{tabular}

ATM, Atmospheres of pressure.

Fluid-percussion injury surgery. All experimental procedures were in compliance with the NIH Guide for the Care and Use of Laboratory Animals and approved by the University of Miami Animal Care and Use Committee. Adult male Sprague-Dawley rats ( $n=127$ total, $2-3$ months old, Charles Rivers Laboratories) were maintained on a $12 \mathrm{~h}$ light/dark cycle and had ad libitum access to food and water. To determine the minimum number of animals needed for these studies, a power analysis was prospectively performed to detect a $20 \%$ difference in water maze probe trial performance between groups at $80 \%$ power with a significance level of 0.05 (Titus et al., 2013b). A sample size of 10 animals per group was obtained. Animals were equally randomized before the experiment to receive moderate parasagittal fluid-percussion injury (FPI) or sham surgery, and treatment with vehicle or $\mathrm{A} 33$. Animals were anesthetized with $3 \%$ isoflurane, $70 \% \mathrm{~N}_{2} \mathrm{O}$, and $30 \% \mathrm{O}_{2}$ and maintained at $1-2 \%$ isoflurane, $70 \% \mathrm{~N}_{2} \mathrm{O}$, and $30 \% \mathrm{O}_{2}$. A $4.8 \mathrm{~mm}$ craniotomy (3.8 $\mathrm{mm}$ posterior to bregma, $2.5 \mathrm{~mm}$ lateral to midline) was made over the right parietal cortex and a beveled 18 gauge syringe hub was secured to the craniotomy site with cyanoacrylate and dental cement. The animals were allowed to recover for 12-16 $\mathrm{h}$ while fasting with water ad libitum, and then were re-anesthetized, intubated and mechanically ventilated (Stoelting) with $0.5-1 \%$ isoflurane, $70 \% \mathrm{~N}_{2} \mathrm{O}$ and $30 \% \mathrm{O}_{2}$. Rocuronium $(10 \mathrm{mg} / \mathrm{kg}$ ) was administered through the tail artery to facilitate ventilation and penicillin/benzathine $(20,000 \mathrm{IU} / \mathrm{kg}, \mathrm{i} . \mathrm{m}$.) was given at the start of the surgery. A moderate (2.0 $\pm 0.1 \mathrm{~atm})$ fluid-percussion pulse (14-16 ms duration) was delivered to the right parietal cortex. Sham-operated rats received all surgical manipulations except for the fluid-percussion pulse. Rectal and temporalis muscle thermistors were used to maintain core and brain temperatures at $36.6^{\circ}-37.2^{\circ} \mathrm{C}$. Blood gases $\left(p \mathrm{O}_{2}\right.$ and $p \mathrm{CO}_{2}$ ), blood $\mathrm{pH}$, and mean arterial blood pressure (MABP) were maintained within normal physiological ranges (Tables 1,2). Buprenorphine $(0.01 \mathrm{mg} / \mathrm{kg}$, s.c. $)$ was administered at the completion of the surgery. Exclusion criteria were as follows: mortality, $>15 \%$ loss of body weight, non-resolving infection at a surgical site, inability to feed or drink, motor paralysis, listlessness, self-mutilation, excessive grooming leading to loss of dermal layers, spontaneous vocalization when touched, or poor grooming habits. Animals were monitored daily after surgery for the first $2 \mathrm{~d}$, then evaluated and weighed every 2 weeks until completion of the experiment. Attrition for sham surgery was $0 \%$ and for TBI surgery was $1 \%$ ( 1 animal that died at the time of surgery due to lung edema). Investigators were blinded to the animal surgery and drug treatment for all behavior, electrophysiology, and histology analyses.

Drug administration. A33 was dissolved in DMSO at $1 \mathrm{mg} / \mathrm{ml}$ and 10 $\mathrm{mm}$ for the behavioral and electrophysiology experiments, respectively. For behavioral testing, A33 $(0.3 \mathrm{mg} / \mathrm{kg}, 6 \mathrm{ml} / \mathrm{kg})$ or vehicle $(6 \mathrm{ml} / \mathrm{kg}, 5 \%$ DMSO in saline) were administered intraperitoneally (i.p.). For hippocampal slice electrophysiology, A33 was diluted in artificial CSF (aCSF) to $300 \mathrm{~nm}$. Final DMSO concentration was $0.003 \%$.

Electrophysiology. At 12 weeks postsurgery, animals were decapitated while anesthetized with $3 \%$ isoflurane, $70 \% \mathrm{~N}_{2} \mathrm{O}$ and $30 \% \mathrm{O}_{2}$ for $4 \mathrm{~min}$. The brain was quickly removed and placed in sucrose-based aCSF containing the following (in $\mathrm{mm}$ ): 110 sucrose, $60 \mathrm{NaCl}, 3 \mathrm{KCl}, 1.25$ $\mathrm{NaH}_{2} \mathrm{PO}_{4}, 28 \mathrm{NaHCO}_{3}, 7 \mathrm{MgCl}_{2}, 0.5 \mathrm{CaCl}_{2}, 5$ D-glucose, equilibrated with $95 \% \mathrm{O}_{2} / 5 \% \mathrm{CO}_{2}$ at $4^{\circ} \mathrm{C}$. The ipsilateral hippocampus was dissected and rapidly sectioned at $4^{\circ} \mathrm{C}$ into transverse slices $400 \mu \mathrm{m}$ thick using a vibrating microtome (Leica). Slices were recovered for $20 \mathrm{~min}$ in 50:50 sucrose-based aCSF and standard aCSF (in mm: $125 \mathrm{NaCl}, 2.5 \mathrm{KCl}, 1.25$ $\mathrm{NaH}_{2} \mathrm{PO}_{4}, 25 \mathrm{NaHCO}_{3}, 10$ D-glucose, $2 \mathrm{CaCl}_{2}, 1 \mathrm{MgCl}_{2}$, saturated with $95 \% \mathrm{O}_{2} / 5 \% \mathrm{CO}_{2}$ ) and then in standard aCSF for $1 \mathrm{~h}$ at room temperature 
Table 2. Physiological parameters

\begin{tabular}{|c|c|c|c|}
\hline Parameter & Treatment & 15 min prior to $\mathrm{FPI}$ & 15 min post-FPI \\
\hline \multirow[t]{4}{*}{ MABP, mmHg } & Sham + vehicle & $118.1 \pm 6.1$ & $117.4 \pm 3.8$ \\
\hline & Sham + A33 & $130.6 \pm 4.1$ & $129.2 \pm 2.7$ \\
\hline & TBI + vehicle & $123.2 \pm 2.7$ & $114.9 \pm 4.2$ \\
\hline & $\mathrm{TBI}+\mathrm{A} 33$ & $118.4 \pm 3.5$ & $111.1 \pm 4.1$ \\
\hline \multirow[t]{4}{*}{ Blood $p \mathrm{O}_{2}$} & Sham + vehicle & $120.2 \pm 5.6$ & $122.6 \pm 4.4$ \\
\hline & Sham + A33 & $158.0 \pm 7.0$ & $153.8 \pm 9.2$ \\
\hline & TBI + vehicle & $155.5 \pm 8.9$ & $142.4 \pm 7.0$ \\
\hline & $\mathrm{TBI}+\mathrm{A} 33$ & $153.4 \pm 5.7$ & $144.2 \pm 6.3$ \\
\hline \multirow[t]{4}{*}{ Blood $p \mathrm{CO}_{2}$} & Sham + vehicle & $39.7 \pm 0.7$ & $38.7 \pm 1.0$ \\
\hline & Sham + A33 & $39.1 \pm 1.4$ & $38.9 \pm 1.1$ \\
\hline & TBI + vehicle & $38.7 \pm 0.7$ & $37.0 \pm 0.6$ \\
\hline & $\mathrm{TBI}+\mathrm{A} 33$ & $39.4 \pm 0.7$ & $36.8 \pm 0.6$ \\
\hline \multirow[t]{4}{*}{ Blood pH } & Sham + vehicle & $7.43 \pm 0.01$ & $7.44 \pm 0.01$ \\
\hline & Sham + A33 & $7.46 \pm 0.01$ & $7.47 \pm 0.01$ \\
\hline & TBI + vehicle & $7.45 \pm 0.01$ & $7.47 \pm 0.01$ \\
\hline & $\mathrm{TBI}+\mathrm{A} 33$ & $7.44 \pm 0.01$ & $7.46 \pm 0.01$ \\
\hline \multirow[t]{4}{*}{ Head temperature, ${ }^{\circ} \mathrm{C}$} & Sham + vehicle & $36.7 \pm 0.0$ & $36.7 \pm 0.1$ \\
\hline & Sham + A33 & $36.7 \pm 0.1$ & $36.7 \pm 0.1$ \\
\hline & TBI + vehicle & $36.7 \pm 0.0$ & $36.7 \pm 0.0$ \\
\hline & $\mathrm{TBI}+\mathrm{A} 33$ & $36.6 \pm 0.0$ & $36.7 \pm 0.0$ \\
\hline \multirow[t]{4}{*}{ Body temperature, ${ }^{\circ} \mathrm{C}$} & Sham + vehicle & $37.0 \pm 0.0$ & $37.0 \pm 0.0$ \\
\hline & Sham + A33 & $37.1 \pm 0.2$ & $37.0 \pm 0.1$ \\
\hline & TBI + vehicle & $37.0 \pm 0.1$ & $37.0 \pm 0.1$ \\
\hline & $\mathrm{TBI}+\mathrm{A} 33$ & $37.1 \pm 0.1$ & $36.9 \pm 0.1$ \\
\hline
\end{tabular}

$\overline{M A B P}$, mean arterial blood pressure; $\mathrm{pO}_{2}$, partial arterial oxygen pressure; $\mathrm{pCO}_{2}$, partial arterial carbon dioxide pressure.

(RT). After equilibration, slices were transferred to a submerged recording chamber and perfused $(2.5-3 \mathrm{ml} / \mathrm{min})$ with aCSF maintained at $31^{\circ} \mathrm{C}$ using a temperature controller (Warner Instruments). Field EPSPs (fEPSPs) were recorded from CA1 stratum radiatum with glass electrodes filled with $2 \mathrm{M} \mathrm{NaCl}(1-3 \mathrm{M} \Omega$ ) using a Multiclamp 700B amplifier (Molecular Devices). Signals were low-pass filtered at $2 \mathrm{kHz}$ and digitized at $20 \mathrm{kHz}$ with a Digidata $1440 \mathrm{~A}$ interface and pClamp 10.4 software (Molecular Devices). The Schaffer collateral pathway was stimulated with a platinum-iridium cluster-stimulating electrode (tip diameter 25 $\mu \mathrm{m}, \mathrm{FHC})$. Input/output (I/O) curves were generated by measuring the fEPSPs in response to stepwise current increases from 20 to $240 \mu \mathrm{A}$. Paired-pulse facilitation (PPF) was measured with stimulus intervals between $12.5-250 \mathrm{~ms}$, with stimulation intensity set at $40-50 \%$ of the maximum fEPSP. Before LTP induction, baseline responses were recorded at $40-50 \%$ of the maximum fEPSP at $0.033 \mathrm{~Hz}$ for at least $20 \mathrm{~min}$. LTP was induced by high-frequency stimulation (HFS) using a single train of 100 pulses delivered at $100 \mathrm{~Hz}$ at test stimulation intensity. A33 (300 nM) or vehicle $(0.003 \%$ DMSO) were bath-applied in aCSF beginning $10 \mathrm{~min}$ before HFS and for $30 \mathrm{~min}$ after HFS. The tetanization response was analyzed by integrating the entire HFS response (total) and integrating the depolarization during last $50 \mathrm{~ms}$ of the HFS to determine steady-state depolarization (Klann et al., 1998). Synaptic fatigue was calculated by measuring each fEPSP during the HFS and normalizing this to the first fEPSP during the HFS (Rutten et al., 2008).

Pharmacokinetic analysis. At 12 weeks after surgery, animals received A33 $(0.3 \mathrm{mg} / \mathrm{kg}, 6 \mathrm{ml} / \mathrm{kg}$, i.p.). At $30 \mathrm{~min}$ after treatment, animals were anesthetized ( $3 \%$ isoflurane, $70 \% \mathrm{~N}_{2} \mathrm{O}$, and $30 \% \mathrm{O}_{2}, 5 \mathrm{~min}$ ) and then decapitated. The ipsilateral and contralateral parietal cortex and hippocampus were dissected, snap frozen with liquid nitrogen, and stored at $-80^{\circ} \mathrm{C}$. The cortical and hippocampal tissue were combined for analysis. At the time of decapitation, trunk blood was collected and diluted with $500 \mathrm{~mm} \mathrm{~K}^{+}$-EDTA, pH 8.0. Blood was centrifuged at $3000 \times g(10 \mathrm{~min}$, $4^{\circ} \mathrm{C}$ ), and plasma was removed and stored at $-80^{\circ} \mathrm{C}$. After precipitation of protein with $0.1 \%$ formic acid, A33 levels were quantified by liquid chromatography-tandem mass spectrometry using an Aquasil C-18 column with a gradient of acetonitrile in $0.1 \%$ formic acid on an Agilent 1200 (Agilent Technologies) followed by mass fragmentation using a SCIEX QTRAP3200 to detect a mass fragment of 144.10. Levels of A33 were normalized to an internal standard.
ELISAs. For the tumor necrosis factor- $\alpha$ (TNF- $\alpha$ ) assessments at $6 \mathrm{~h}$ postsurgery, animals received either A33 $(0.3 \mathrm{mg} / \mathrm{kg}$, i.p.) or vehicle $(5 \%$ DMSO in saline, $6 \mathrm{ml} / \mathrm{kg}$ ) at $30 \mathrm{~min}$ and $5 \mathrm{~h}$ postsurgery. At $6 \mathrm{~h}$ after surgery, animals were anesthetized ( $3 \%$ isoflurane, $70 \% \mathrm{~N}_{2} \mathrm{O}$, and $30 \%$ $\mathrm{O}_{2}, 5 \mathrm{~min}$ ) and decapitated. For the TNF- $\alpha$ and interleukin (IL) $-1 \beta$ assessments at 3 months postsurgery, animals received no treatment after surgery and were decapitated under anesthesia (3\% isoflurane, $70 \%$ $\mathrm{N}_{2} \mathrm{O}$, and $30 \% \mathrm{O}_{2}, 5 \mathrm{~min}$ ) at 3 months postsurgery. The ipsilateral parietal cortex and hippocampus were rapidly dissected on ice, snap frozen in liquid nitrogen and stored at $-80^{\circ} \mathrm{C}$ until use. Tissue was briefly sonicated at $4^{\circ} \mathrm{C}(10 \mathrm{~s}$, setting 2 , Branson sonifier 450) in $5 \mathrm{vol} / \mathrm{wt}$ for the parietal cortex and $10 \mathrm{vol} / \mathrm{wt}$ for the hippocampus in lysis buffer $[15 \mathrm{~mm}$ Tris, pH 7.6, 0.25 м sucrose, 1 mм $\mathrm{MgCl}_{2}$, 1 mм EGTA, 1 mм DTT, 1.25 $\mu \mathrm{g} / \mathrm{ml}$ pepstatin A, $10 \mu \mathrm{g} / \mathrm{ml}$ leupeptin, $25 \mu \mathrm{g} / \mathrm{ml}$ aprotinin, $0.5 \mathrm{~mm}$ PMSF, $0.1 \mathrm{~mm} \mathrm{Na}_{3} \mathrm{VO}_{4}, 50 \mathrm{~mm} \mathrm{NaF}, 2 \mathrm{~mm} \mathrm{Na}_{4} \mathrm{P}_{2} \mathrm{O}_{7}, 1 \times$ phosphatase inhibitor cocktail set II (EMD Millipore), 0.1\% Igepal CA-630]. Total protein was assayed using a Coomassie Plus assay kit (Thermo Fisher Scientific). Each sample was assayed in duplicate following the manufacturer's protocol (Rat TNF- $\alpha$ Quantikine ELISA RTA00; Rat IL-1 $\beta /$ IL1F2 Quantikine ELISA RLB00; R\&D Systems).

Western blot analysis. At 3 months after surgery, animals were anesthetized ( $3 \%$ isoflurane, $70 \% \mathrm{~N}_{2} \mathrm{O}$, and $30 \% \mathrm{O}_{2}, 5 \mathrm{~min}$ ) and decapitated, and the ipsilateral hippocampus was rapidly dissected on ice, snap frozen in liquid nitrogen and stored at $-80^{\circ} \mathrm{C}$. Tissue was homogenized on ice with a Dounce homogenizer in $750 \mu$ l of lysis buffer: $15 \mathrm{~mm}$ Tris, $\mathrm{pH}$ 7.6, 0.25 м sucrose, $1 \mathrm{~mm} \mathrm{MgCl}_{2}$, 1 mM EGTA, 1 mM DTT, $1 \mu \mathrm{m}$ microcystinLR, $1.25 \mu \mathrm{g} / \mathrm{ml}$ pepstatin A, $10 \mu \mathrm{g} / \mathrm{ml}$ leupeptin, $25 \mu \mathrm{g} / \mathrm{ml}$ aprotinin, 0.5 mM PMSF, $1 \times$ phosphatase inhibitor cocktail set II (EMD Millipore), 0.1 $\mathrm{mm} \mathrm{Na}_{3} \mathrm{VO}_{4}, 50 \mathrm{~mm} \mathrm{NaF}$, and $2 \mathrm{~mm} \mathrm{Na}_{4} \mathrm{P}_{2} \mathrm{O}_{7}$. Total protein was measured using a Coomassie Plus assay kit (Thermo Fisher Scientific). Samples were boiled with sample buffer for $9 \mathrm{~min}$ at $95^{\circ} \mathrm{C}$. Equal amounts of protein ( 25 or $40 \mu \mathrm{g} /$ lane) were electrophoresed on $4-15 \%$ SDS-PAGE gradient gels (Bio-Rad Laboratories) or 12.5\% SDS-PAGE gels and transferred to Immobilon-P PVDF membranes (EMD Millipore). Membranes were probed with antibodies against PDE4B (1:500; H-56, Santa Cruz Biotechnology), phospho-CREB (1:1000; 87G3, Cell Signaling Technology) and CREB (1:500; 86B10, Cell Signaling Technology), and then stripped and reprobed with antibodies against $\beta$-actin $(1: 10,000$; AC-15, Sigma-Aldrich). Blots were visualized with horseradish peroxidase-conjugated secondary antibodies (1:1000; anti-rabbit IgG 7074, anti-mouse IgG 7076, Cell Signaling Technology) and enhanced chemiluminescence (Cell Signaling Technology) or Pierce ECL Plus Substrate (Thermo Fisher Scientific) and were developed on X-ray film (Phenix Research Products). Films were densitized using ImageJ 1.48v (NIH). Levels of each protein were normalized to $\beta$-actin within each sample and then normalized to average protein levels in sham animals.

Fear conditioning. Beginning at 12 weeks postsurgery, animals were tested serially on fear conditioning (12 and 16 weeks postsurgery), water maze (13 weeks postsurgery), working memory (14 weeks postsurgery), shock threshold ( 16 weeks postsurgery), and then perfused at 5 months postsurgery for atrophy and microglia analyses (see Fig. $3 A$ ). For cue and contextual fear conditioning at 12 weeks postsurgery, animals were first habituated to the apparatus $(30.5 \times 24.1 \times 21 \mathrm{~cm}$, Coulbourn Instruments) for $10 \mathrm{~min}$ to facilitate contextual fear conditioning (Rudy and O'Reilly, 1999). On the following day, at $30 \mathrm{~min}$ before training, animals received $\mathrm{A} 33$ or vehicle treatment. For training, animals were placed in the apparatus for $120 \mathrm{~s}$, and then a $30 \mathrm{~s}$ tone $(75 \mathrm{~dB}, 2.8 \mathrm{kHz})$ was delivered that coterminated with a $1 \mathrm{~mA}$ foot shock ( $1 \mathrm{~s}$ duration). Animals remained in the box for $60 \mathrm{~s}$ post-shock. The apparatus was cleaned with $70 \%$ ethanol between trials. At $24 \mathrm{~h}$ and 1 month after training, contextual fear conditioning was evaluated by placing the animals in the apparatus and measuring freezing for $5 \mathrm{~min}$. Contextual fear conditioning comparisons were made between freezing on the training day before cue presentation (designated as training freezing) and freezing in the context on the testing days. Cue fear conditioning was evaluated at $25 \mathrm{~h}$ and 1 month after training by placing animals in an altered chamber with changed ambient light, background noise, texture on the walls and floor, as well as a novel odorant. Cue fear conditioning comparisons were made between freezing on the testing day in the novel context before cue pre- 
sentation (designated as baseline freezing) and freezing during the cue presentation. Video-based analysis was used to quantify freezing behavior (FreezeFrame 3.32, Coulbourn Instruments). At the completion of fear conditioning assessments, shock threshold was assessed at 16 weeks postsurgery. Animals received vehicle or A33 at 30 min before shock threshold testing and then received a $1 \mathrm{~s}$ foot shock every $30 \mathrm{~s}$ in $0.02 \mathrm{~mA}$ increments beginning at $0.1 \mathrm{~mA}$. The minimum shock intensity to elicit a flinch, jump, or vocalization was recorded.

Water maze. At 13 weeks postsurgery, animals received A33 or vehicle at $30 \mathrm{~min}$ before training in the water maze on each acquisition day. Acquisition consisted of four trials per day over $4 \mathrm{~d}$ with an intertrial interval of 4-6 min. Maximum trial duration did not exceed $60 \mathrm{~s}$. If the animal failed to navigate to the platform within $60 \mathrm{~s}$, it was then guided to the platform. Animals remained on the platform for $10 \mathrm{~s}$. Path length to reach the platform, escape latency, swim velocity, thigmotaxis, and percentage time spent floating were measured. Thigmotaxis was defined as the time that an animal spent swimming within $13.5 \mathrm{~cm}$ of the wall. Percentage time spent floating was defined as the amount of time an animal was immobile below a threshold of $1.5 \mathrm{~cm} / \mathrm{s}$. At $24 \mathrm{~h}$ after the final acquisition day, a probe trial ( $60 \mathrm{~s}$ duration) was given with the platform removed. Animals did not receive any drug treatment on the day of the probe trial. Time spent in each quadrant, number of platform zone crossings and swim velocity were measured during the probe trial. Data were analyzed using EthoVision XT 10 software (Noldus Information Technology).

Working memory. At 14 weeks postsurgery, working memory was assessed using a delayed match-to-place task in the water maze (Hoskison et al., 2009). Animals received A33 or vehicle 30 min before testing on each day. Four paired trials were given each day for $2 \mathrm{~d}$; trial duration was $60 \mathrm{~s}$. Time between each pair of trials was 4-6 min. The hidden platform location remained invariant only for each pair of trials. Upon reaching the platform, the animal remained on the platform for $10 \mathrm{~s}$. After a $5 \mathrm{~s}$ delay, the animal was released from the same site into the water to again search for the hidden platform in the same location. Escape latencies on the first location trial and subsequent match trial were measured. Data shown are from Day 2.

Histology. At 5 months postsurgery, animals were anesthetized (3\% isoflurane, $70 \% \mathrm{~N}_{2} \mathrm{O}$ and $30 \% \mathrm{O}_{2}, 5 \mathrm{~min}$ ) and transcardially perfused with saline $(80 \mathrm{ml})$ and then $4 \%$ paraformaldehyde $(210 \mathrm{ml})$ in $0.1 \mathrm{M}$ phosphate buffer, $\mathrm{pH}$ 7.4. The brains were sectioned coronally $(10 \mu \mathrm{m}$ thick) in a stereological series (150 $\mu \mathrm{m}$ apart). For atrophy analysis, serial sections were stained with hematoxylin and eosin plus Luxol fast blue. The ipsilateral and contralateral hippocampus and cortex between bregma levels -3.8 to $-5.8 \mathrm{~mm}$ were traced in serial sections $(150 \mu \mathrm{m}$ apart) at $4 \times$ magnification using Neurolucida 10.50.2 (MBF Bioscience) and an Olympus BX51TRF microscope (Olympus America). The contralateral and ipsilateral volumes were calculated using Neurolucida 10.50.2 software. To account for differences in tissue shrinkage, the ipsilateral volume was subtracted from the contralateral volume, and then normalized to the contralateral volume to calculate the percentage of atrophy.

For microglia quantification, sections were antigen-retrieved using citrate buffer ( $10 \mathrm{~mm}$ citrate, $\mathrm{pH}$ 6.0) for $20 \mathrm{~min}$. Sections were blocked for $1 \mathrm{~h}$ at RT in blocking buffer (PBS containing 3\% normal goat serum and $0.4 \% \mathrm{TX}-100)$, then incubated overnight at $4^{\circ} \mathrm{C}$ with anti-ionized calcium binding adaptor molecule-1 antibody (Iba-1; 1:500; 019-19741, Wako Chemicals) in blocking buffer. Sections were rinsed with PBS, and then incubated with anti-rabbit secondary antibody conjugated to AlexaFluor 594 (1:200; A11037, Invitrogen) for $2 \mathrm{~h}$ at RT in blocking buffer. Sections were mounted using VectaShield DAPI mounting medium for fluorescence (H-1200, Vector Laboratories). All sections were processed in parallel for immunohistochemistry. Bregma levels $-3.3,-4.3$, and $-5.3 \mathrm{~mm}$ were selected for analysis because the epicenter of the fluidpercussion was $-3.8 \mathrm{~mm}$ posterior to bregma. Two sections at each bregma level were quantified and averaged. The ipsilateral parietal cortex and hippocampus were contoured at $4 \times$ magnification using an Olympus BX51 microscope (Olympus America) and StereoInvestigator 5.65 software (MicroBrightField). Iba-1-positive cells were counted at $60 \times$ magnification (1.42 NA objective) using a $75 \times 75 \mu \mathrm{m}$ counting frame in
30 randomly placed sampling sites. Ramified microglia were identified as cells with a small soma and having thin, branched processes, intermediate microglia were cells with a large soma and long, thick processes and ameboid microglia were defined as cells with a large soma and few, short processes. Confocal images were acquired with an Olympus FV1000 laser scanning confocal microscope (Olympus America) and a $20 \times$ objective $(\mathrm{NA}=0.75$, digital zoom 2.0). DAPI and Iba- 1 expression were captured using excitation wavelengths 405 and $543 \mathrm{~nm}$, respectively. Multi-area confocal scans were taken at $1.14 \mu \mathrm{m} z$-steps keeping all parameters constant (laser power, HV, gain, offset, and pinhole). Final images were rendered using Imaris 8.2.0 software (Bitplane).

Data analysis. Data presented are mean \pm SEM. Significance was designated at $p<0.05$. Statistical comparisons were made using GraphPad Prism 6.05 and SigmaPlot 12.0. I/O responses, PPF, LTP, synaptic fatigue during tetanization, physiological data during the surgery, cue and contextual fear conditioning, shock threshold, water maze data, and working memory data were analyzed by three-way ANOVA (factors surgery $X$ drug treatment $\times$ trial or time) followed by two-way ANOVA (factors surgery $\times$ drug treatment) for significant interactions and Tukey's HSD correction for multiple comparisons. Depolarization during tetanization, A33 concentration in brain tissue, Western blot data, swim velocity, atrophy, and Iba- 1 cell counts were analyzed with a two-way ANOVA (factors surgery $X$ drug treatment) and Tukey's HSD correction for multiple comparisons. TNF- $\alpha$ levels were analyzed with a one-way ANOVA and Tukey's HSD correction for multiple comparisons. A33 plasma levels and IL- $1 \beta$ levels were analyzed with an unpaired Student's $t$ test.

\section{Results}

Persistent deficits in learning and memory are a commonality among TBI survivors (Lew et al., 2006). To determine whether hippocampal synaptic plasticity changes are involved in these persistent learning and memory deficits and whether PDE4B inhibition could rescue these changes, we assessed synaptic plasticity mechanisms in hippocampal slices from sham and TBI animals at 3 months after surgery. The Schaffer collateral pathway was stimulated and recordings were made in stratum radiatum of area CA1 (Fig. 1). Hippocampal slices were treated with vehicle $(0.003 \%$ DMSO in saline) or a PDE4B inhibitor, A33 at $300 \mathrm{~nm}$. This concentration is tenfold higher than the $\mathrm{IC}_{50}$ against PDE4B3 measured in vitro $(27 \pm 2 \mathrm{nM}, n=20)$. Basal synaptic transmission was significantly depressed in slices from TBI animals compared with sham animals (main effect of surgery: $\left.F_{(1,350)}=123.95, p<0.001\right)$ and a significant interaction of surgery $\times$ drug treatment was observed $\left(F_{(1,350)}=20.19, p<0.001\right)$. A33 bath application to TBI slices reversed the depression in basal synaptic transmission (Fig. 1A). To determine whether presynaptic release mechanisms were involved, PPF was assessed. TBI significantly decreased PPF (main effect of surgery: $F_{(1,210)}=$ $6.18, p=0.014)$, although there was not a significant interaction of surgery $\times$ drug treatment (Fig. $1 B$ ). However, LTP expression was impaired in hippocampal slices from TBI animals, and this was improved with A33 bath application (Fig. $1 C$; main effect of surgery: $F_{(1,1320)}=307.61, p<0.001$; main effect of drug treatment: $F_{(1,1320)}=327.94, p<0.001$; interaction of surgery $\times$ drug treatment: $\left.F_{(1,1320)}=284.22, p<0.001\right)$. Analysis of responses during the maintenance phase of LTP at 45-60 min post-tetanus revealed a significant interaction of surgery $\times$ drug treatment $\left(F_{(1,22)}=7.51, p=0.012\right)$. A33 significantly rescued the maintenance phase of hippocampal LTP (Fig. 1D). The changes in LTP maintenance were not due to differences in depolarization during the tetanus (Fig. $1 E$ ). Both total depolarization and steadystate depolarization levels during the tetanization were not significantly different between sham and TBI animals treated with vehicle or A33 (Fig. $1 F$ ). Synaptic fatigue during the tetanization was also not significantly different between sham and TBI 

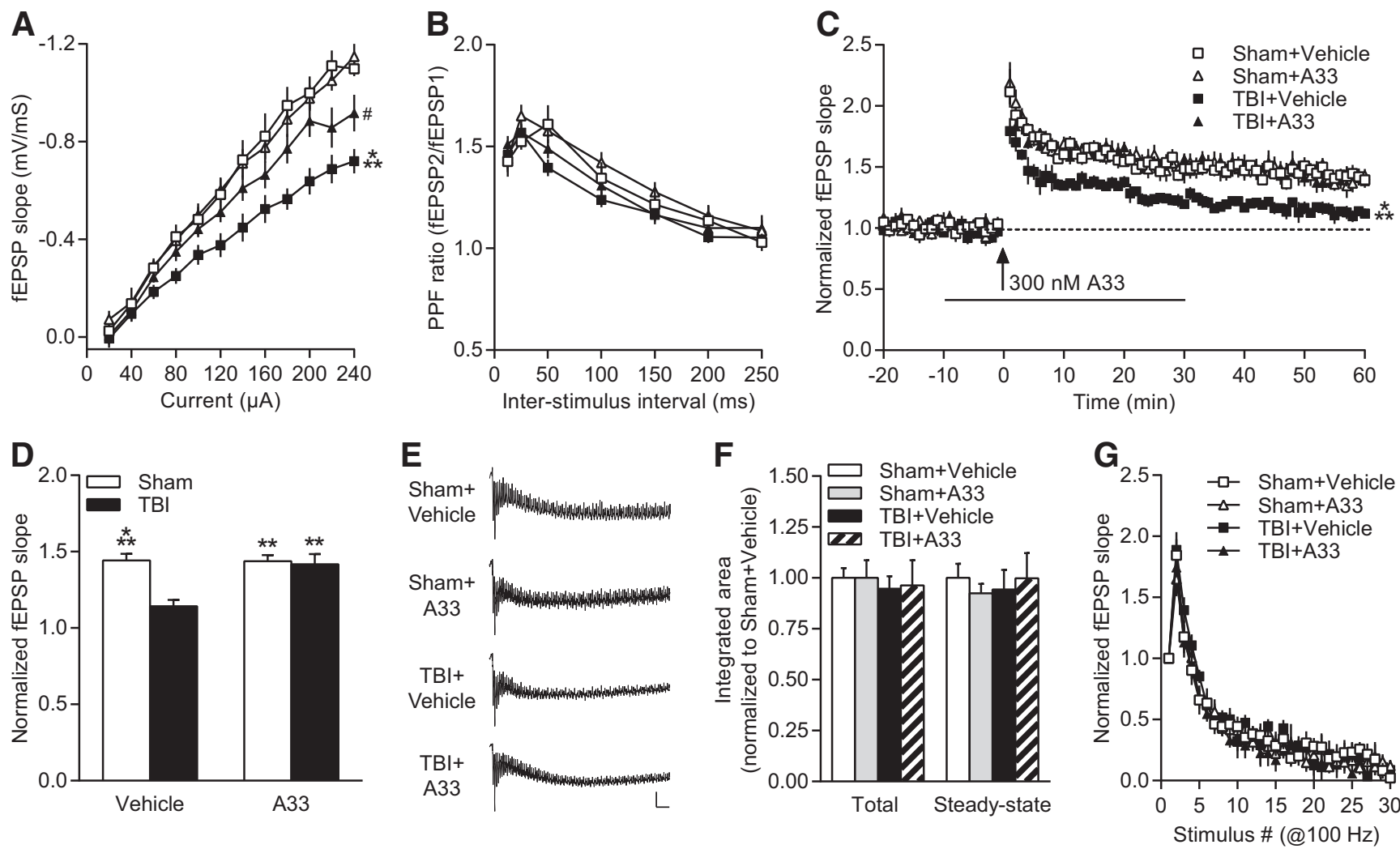

Figure 1. Basal synaptic transmission and LTP were enhanced with the PDE4B inhibitor A33 in hippocampal slices from TBI animals at 3 months postinjury. $A$, Input/output (I/0) responses in stratum radiatum of area CA1 to Schaffer collateral stimulation were significantly shifted downward in hippocampal slices from TBI animals treated with vehicle $(0.003 \%$ DMSO). Bath application of A33 (300 nM) to slices significantly reversed the TBI-induced depression of the fEPSP slope. Sham + vehicle: $n=8$ slices $/ 6$ animals; Sham + A33: $n=8$ slices $/ 5$ animals; TBI + vehicle: $n=10$ slices/ 6 animals; TBI+A33: $n=8$ slices $/ 6$ animals; ${ }^{* * *} p<0.001$ TBI+ vehicle versus Sham + vehicle, Sham +A33, or TBI+A33; $p<0.001$ TBI+A33 versus Sham + vehicle, or Sham + A33; three-way ANOVA with Tukey's HSD correction for multiple comparisons. B, PPF was significantly decreased following TBI ( $p=0.014$ Sham vs TBI), but not improved with A33 treatment ( $300 \mathrm{~nm}$ ). Data represent the ratio of the second fEPSP slope to the first fEPSP slope. Sham + vehicle: $n=8$ slices $/ 6$ animals; Sham + A33: $n=8$ slices $/ 5$ animals; TBI + vehicle: $n=10$ slices $/ 6$ animals; $\mathrm{TBI}+\mathrm{A33}: n=8$ slices $/ 6$ animals. C, A33 significantly rescued TBI-induced deficits in hippocampal LTP. A33 (300 nm) or vehicle (0.003\% DMS0) were bath applied $10 \mathrm{~min}$ before and for $30 \mathrm{~min}$ after tetanization (bar). Hippocampal LTP was induced with $1 \times 100 \mathrm{~Hz}$ tetanization, $1 \mathrm{slong}$ (arrow). fEPSP slopes were normalized to baseline before tetanization. ${ }^{* * *} p<0.001$ TBI + vehicle versus Sham + vehicle, Sham + A33, or TBI + A33; three-way ANOVA with Tukey's HSD correction for multiple comparisons. D, Average of fEPSP slopes from 45 to 60 min post-tetanization. ${ }^{* *} p<0.01$, ${ }^{* * *} p<0.001$ versus TBI + vehicle; two-way ANOVA with Tukey's HSD correction for multiple comparisons. $\boldsymbol{E}$, Representative traces during the high-frequency tetanization. Scale bars: $0.5 \mathrm{mV}, 75$ $\mathrm{ms} . \boldsymbol{F}$, Total depolarization levels during tetanization and steady-state depolarization levels during the last $50 \mathrm{~ms}$ of the tetanization response were similar between slices from sham animals and TBI animals treated with vehicle or A33. G, Synaptic fatigue during the tetanization. No significant differences were observed between groups. $\mathbf{C}-\mathbf{G}$, Sham + vehicle: $n=7$ slices/ 6 animals; Sham +A33: $n=6$ slices $/ 5$ animals; TBI + vehicle: $n=6$ slices $/ 6$ animals; TBI + A33: $n=7$ slices $/ 6$ animals.

animals treated with either vehicle or A33 (Fig. 1G). These results indicate that the PDE4B inhibitor, A33, rescues expression of hippocampal LTP and improves basal synaptic transmission at 3 months after TBI.

Next, we evaluated the distribution of A33 to the brain in rats after systemic administration and the impact of brain injury on this distribution (Fig. 2). Animals received sham surgery or moderate parasagittal FPI. At 3 months postsurgery, animals were treated systemically with A33 at $0.3 \mathrm{mg} / \mathrm{kg}$ (i.p.). At $30 \mathrm{~min}$ after treatment, a time point relevant to the biochemical and behavioral analyses described below, plasma and brain tissue were harvested to measure A33 levels. Plasma levels of A33 were identical between sham and TBI animals after intraperitoneal dosing. However, brain levels of A33 trended higher in TBI animals compared with sham animals when measured in either the ipsilateral or contralateral cortex (effect of surgery: $F_{(1,8)}=4.41, p=0.069$ ), although this difference was not statistically significant (Fig. 2A). $\mathrm{A} 33$ has low brain distribution, with a similar $\mathrm{B} / \mathrm{P}$ distribution of $2.4 \pm 0.2 \%$ and $3.2 \pm 0.4 \%$ in sham and TBI animals, respectively ( $n=6 /$ group). At the intraperitoneal dose of $0.3 \mathrm{mg} / \mathrm{kg}$, brain levels were 4 - to 5 -fold higher than the $\mathrm{IC}_{50}$ against PDE4B3 measured in vitro $(27 \mathrm{nM}$ or $10.4 \mathrm{ng} / \mathrm{ml})$. These results indicate that $\mathrm{A} 33$ can attain relevant concentrations in the brain against the PDE4B target.

PDE4 knock-out studies in inflammation models have revealed that PDE4B, but not PDE4A or PDE4D, regulates expression of the proinflammatory cytokine TNF- $\alpha$ in circulating leukocytes and peritoneal resident macrophages (Ashkenazi, 2002; Jin and Conti, 2002; Jin et al., 2005). To determine whether TNF- $\alpha$ was elevated in the injured brain at 3 months postinjury, the ipsilateral parietal cortex and hippocampus were assayed by ELISA for TNF- $\alpha$ levels. TNF- $\alpha$ was not detectable at 3 months postinjury in either brain region. We also assayed for IL- $1 \beta$ levels, which were detectable, but not significantly elevated in the ipsilateral, injured parietal cortex and hippocampus (Sham cortex or Sham hippocampus not detectable, TBI cortex $0.54 \pm 0.26 \mathrm{pg} / \mathrm{mg}$ protein, TBI hippocampus $1.85 \pm 1.03 \mathrm{pg} / \mathrm{mg}$ protein, $n=$ 6/group). Next, to determine whether A33 can reduce TNF- $\alpha$ levels in the injured brain, we assessed TNF- $\alpha$ levels at $6 \mathrm{~h}$ postsurgery. We chose this time point because previous studies have established that TBI elevates TNF- $\alpha$ levels maximally within 3-8 $\mathrm{h}$ after injury and returns to non-injured levels by $24 \mathrm{~h}$ after TBI 
(Taupin et al., 1993; Yakovlev and Faden, 1994; Fan et al., 1996; Knoblach et al., 1999; Vitarbo et al., 2004; Lotocki et al., 2006; Shojo et al., 2010; Ferreira et al., 2013; Su et al., 2014; Tsai et al., 2015). At $30 \mathrm{~min}$ postinjury, as well as $1 \mathrm{~h}$ before kill, animals received $0.3 \mathrm{mg} / \mathrm{kg}$ A33 (i.p.) or vehicle. TNF- $\alpha$ levels were significantly increased in TBI animals and A33 treatment significantly reduced this increase in TNF- $\alpha$ (Fig. $2 B$ ). These data demonstrate that systemic administration of A33 can inhibit a signaling pathway that can be regulated by PDE4B after TBI. Western blots of the hippocampus at 3 months after sham surgery or TBI indicated that PDE4B1/3, 4B4 and 4B2 isoforms were present in the hippocampus (Fig. 2C). No significant differences were observed between sham and TBI animals (Fig. 2D). These results indicate that several PDE4B isoforms are present in the injured brain, but are not upregulated in the chronically injured hippocampus at 3 months postinjury.

Next, to determine whether PDE4B inhibition by A33 would improve chronic learning and memory deficits after TBI, animals received sham surgery or moderate FPI and were allowed to recover for 3 months with no treatment (Tables 1, 2). They were then tested serially on fear conditioning (12 and 16 weeks postsurgery), water maze (13 weeks postsurgery) and working memory (14 weeks postsurgery; Fig. $3 A$ ). Animals received either vehicle or A33 treatment 30 min before training on each behavioral task. During the surgery, physiological parameters of MABP, blood $\mathrm{pO}_{2}$ and $p \mathrm{CO}_{2}$ levels, blood $\mathrm{pH}$, and head and body temperature were monitored. These parameters remained in physiological range for all animals except for one TBI animal. This one TBI animal was excluded due to mortality at the time of surgery, which died within $1 \mathrm{~h}$ after brain trauma from lung edema. The atmospheric levels of the fluid-pulse were not significantly different between TBI animals randomized to vehicle versus A33 treatment. All animal groups had weight gains by the end of the behavioral testing at 5 months postsurgery and these gains were not significantly different between treatment groups (main effect of time: $F_{(1,60)}=301.48, p<0.001$ ).

Cue and contextual fear conditioning were assessed at 12 weeks postsurgery (Fig. 3). Animals received either vehicle or A33 $(0.3 \mathrm{mg} / \mathrm{kg}$, i.p. $)$ at $30 \mathrm{~min}$ before fear conditioning and were then tested for fear conditioning recall in the absence of any drug treatment at $24 \mathrm{~h}$ and 1 month after training. This dose was chosen based on data demonstrating antidepressant effects of $\mathrm{A} 33$ in the mouse forced swim test $\left(\mathrm{ED}_{50}=0.1 \mathrm{mg} / \mathrm{kg}\right.$, James O'Donnell personal communication). A three-way ANOVA of contextual fear conditioning indicated a significant interaction of surgery $\times$ drug treatment $\times$ trial (Fig. $3 B ; F_{(2,90)}=3.43, p=$ $0.037)$. No significant differences in freezing during training were observed between animal groups. At both $24 \mathrm{~h}$ and 1 month after training, contextual fear conditioning was not significantly dif-
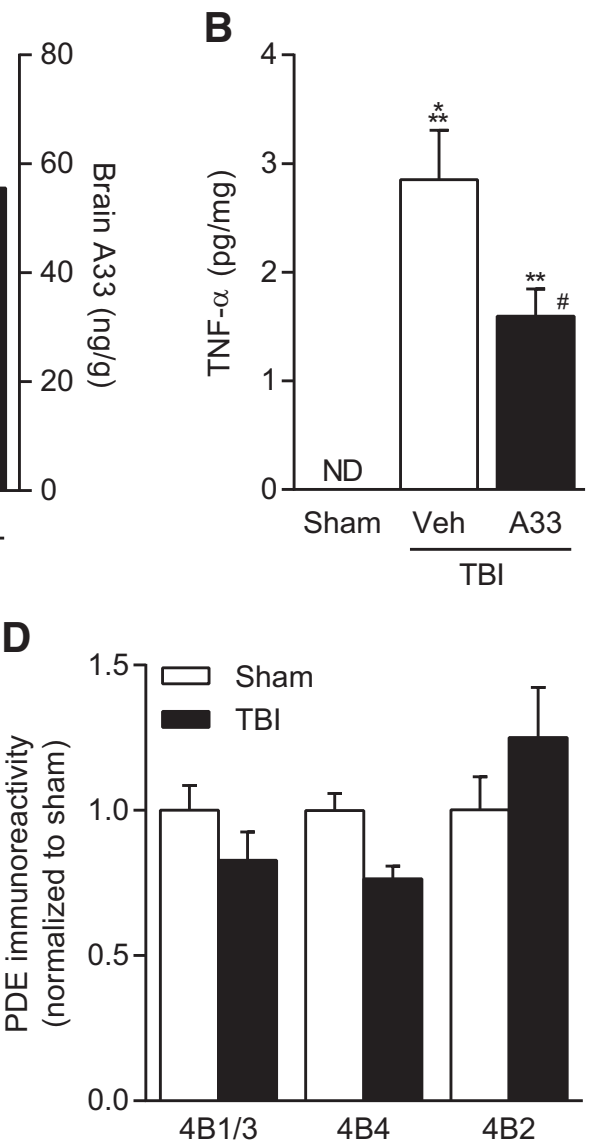

Figure 2. Levels of A33 in the brain and plasma with systemic administration of A33 and effects on TNF- $\alpha$ levels. $A, A 33$ levels were assessed in the plasma and brain at $30 \mathrm{~min}$ after intraperitoneal administration $(0.3 \mathrm{mg} / \mathrm{kg})$. Sham and TBI animals were hippocampus at 3 months after TBI. $D$, Densitometric results. PDE4B1/3, 4B4, or 4 B2 levels did not significantly change at 3 months

ferent between sham animals treated with vehicle compared with sham animals treated with A33. TBI animals treated with vehicle demonstrated significantly less contextual fear conditioning compared with sham animals treated with vehicle or TBI animals treated with A33 when tested at $24 \mathrm{~h}$ after fear conditioning (surgery $\times$ drug treatment interaction: $\left.F_{(1,30)}=7.52, p=0.010\right)$. When animals were re-assessed without drug treatment at 1 month after fear conditioning, TBI animals treated with vehicle still froze significantly less compared with TBI animals treated with $\mathrm{A} 33$ at 1 month after fear conditioning (surgery $\times$ drug treatment interaction: $\left.F_{(1,30)}=4.39, p=0.045\right)$. For cue fear conditioning, a significant interaction of surgery $\times$ drug treatment $\times$ trial was observed with a three-way ANOVA (Fig. $3 C$; $\left.F_{(3,120)}=4.59, p=0.004\right)$. A main effect of drug treatment was observed in baseline freezing in the novel chamber at $24 \mathrm{~h}$ (vehicle vs A33 treatment: $\left.F_{(1,30)}=4.57, p=0.041\right)$ and 1 month (vehicle vs A33 treatment: $F_{(1,30)}=7.29, p=0.011$ ) after fear conditioning, and there was no significant interaction of surgery $\times$ drug treatment for either time point in baseline freezing. When freezing in response to the cue was assessed, there was a significant interaction of surgery $\times$ drug treatment at both $24 \mathrm{~h}$ $\left(F_{(1,30)}=7.75, p=0.009\right)$ and 1 month after training $\left(F_{(1,30)}=\right.$ $11.51, p=0.002)$. At both assessment time points, cue fear con- 

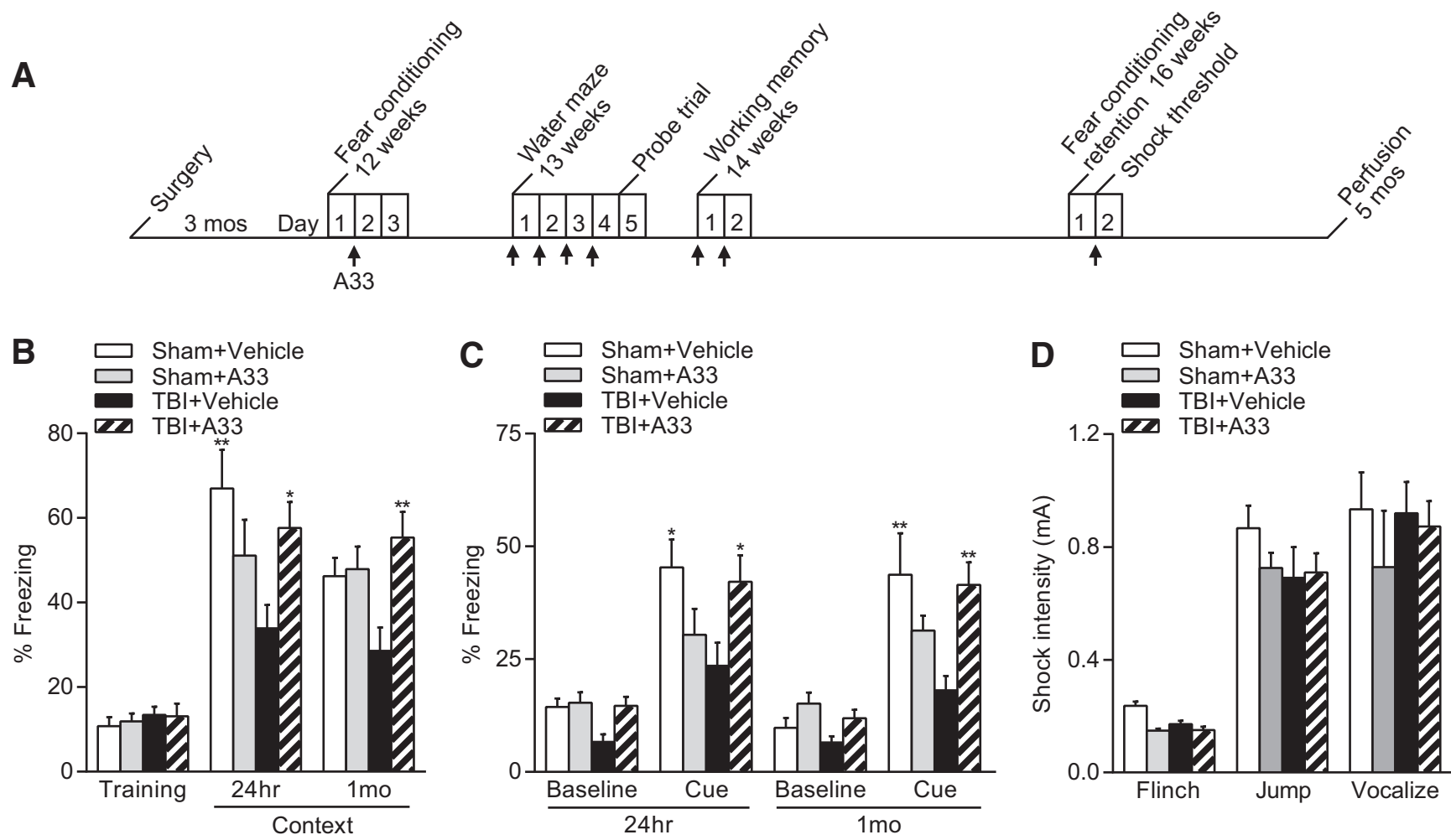

Figure 3. Contextual and cue fear conditioning impairments in TBI animals at 3 months postinjury were rescued by A33 treatment. $A$, Treatment scheme and timeline of behavioral analysis. Animals recovered for 3 months after surgery and then were tested serially on fear conditioning, water maze, working memory, retention of fear conditioning, and shock threshold before perfusion at 5 months postsurgery. A33 or vehicle were administered $30 \mathrm{~min}$ before behavioral training on the indicated days (arrows). B, Contextual fear conditioning at $24 \mathrm{~h}$ and $1 \mathrm{month}$ after training. TBI+ vehicle animals froze significantly less than Sham + vehicle animals or TBI + A33 animals at both $24 \mathrm{~h}$ and $1 \mathrm{month}$ after training. C, Cue fear conditioning was significantly decreased in TBI+ vehicle animals compared with Sham + vehicle or TBI+A33 animals. D, Shock threshold sensitivity was similar between all animal groups. Sham + vehicle: $n=6$; Sham + A33: $n=7 ; \mathrm{TBI}+$ vehicle: $n=10 ; \mathrm{TBI}+\mathrm{A33}: n=11 ;{ }^{*} p<0.05,{ }^{* *} p<0.01$ versus TBI+ vehicle; two-way ANOVA with Tukey's HSD correction for multiple comparisons.

ditioning was significantly decreased in TBI animals treated with vehicle compared with sham animals treated with vehicle or TBI animals treated with A33. There were no significant differences in cue fear conditioning when tested for retrieval at $24 \mathrm{~h}$ or 1 month after training for sham animals treated with vehicle versus A33. These fear conditioning differences were not due to changes in shock sensitivity since the minimal shock threshold to elicit a flinch, jump or vocalization was not significantly different between animal groups (Fig. 3D).

Next, to determine whether A33 would improve learning in another hippocampal-dependent learning task, the same cohort of animals were tested in a water maze at 13 weeks postsurgery using a hidden platform (Fig. 4). Escape latency (Fig. 4A) and path length (Fig. $4 B$ ) to find the hidden platform were significantly impaired in TBI animals compared with sham animals, although there was no significant interaction between surgery $x$ drug treatment $X$ acquisition day or main effect of drug treatment for escape latency (main effect of surgery for escape latency: $F_{(1,120)}=34.20, p<0.001$; main effect of surgery for path length: $\left.F_{(1,120)}=13.27, p<0.001\right)$. There was a main effect of drug treatment for path length during acquisition $\left(F_{(1,120)}=6.71, p=\right.$ 0.011). For both escape latency and path length, a main effect of acquisition day was observed (escape latency: $F_{(3,120)}=48.76$, $p<0.001$; path length: $\left.F_{(3,120)}=43.35, p<0.001\right)$. As PDE4B is involved in mediating anxiety, we measured swim velocity (Fig. $4 C$ ), thigmotaxis (Fig. 4D), and percentage time floating (Fig. $4 E$ ) during water maze acquisition. No significant differences in swim velocity, thigmotaxis, or percentage time floating during acquisi- tion were found between surgery and drug treatment groups. A main effect of acquisition day was observed for thigmotaxis $\left(F_{(3,120)}=56.93, p<0.001\right)$, with significantly more thigmotaxis occurring on acquisition Day 1 versus Days 2, 3 and $4(p<$ $0.001)$, as well as Day 2 versus Day $4(p=0.002)$. Similarly, a main effect of acquisition day was observed for percentage time floating $\left(F_{(3,120)}=3.39, p=0.020\right)$, with significantly more floating occurring on acquisition Day 1 compared with acquisition Days 3 and $4(p<0.05)$. To assess the search strategy, animals were probed at $24 \mathrm{~h}$ after the final acquisition day (Fig. $4 F$ ). Analysis of time spent in each quadrant indicated a significant interaction for surgery $\times$ drug treatment $\times$ quadrant $\left(F_{(3,120)}=\right.$ $3.65, p=0.015)$. TBI animals treated with vehicle spent significantly less time in the target quadrant compared with sham animals treated with vehicle or A33, or TBI animals treated with A33 (surgery $\times$ drug treatment interaction $F_{(1,30)}=4.92, p=0.034$ ). The number of platform zone crossings were also significantly less in TBI animals treated with vehicle versus A33, or sham animals treated with vehicle or A33 (Fig. $4 G$; surgery $\times$ drug treatment interaction: $\left.F_{(1,30)}=6.47, p=0.016\right)$. No significant differences were observed in sham animals treated with vehicle versus A33 for time spent in the target quadrant or number of platform zone crossings during the probe trial. Swim velocity during the probe trial was not significantly different between surgery and drug treatment groups (data not shown). These results indicate that A33 treatment significantly improves long-term spatial memory retention.

Working memory is another modality significantly impaired in TBI survivors (McAllister et al., 2006). To assess this memory 

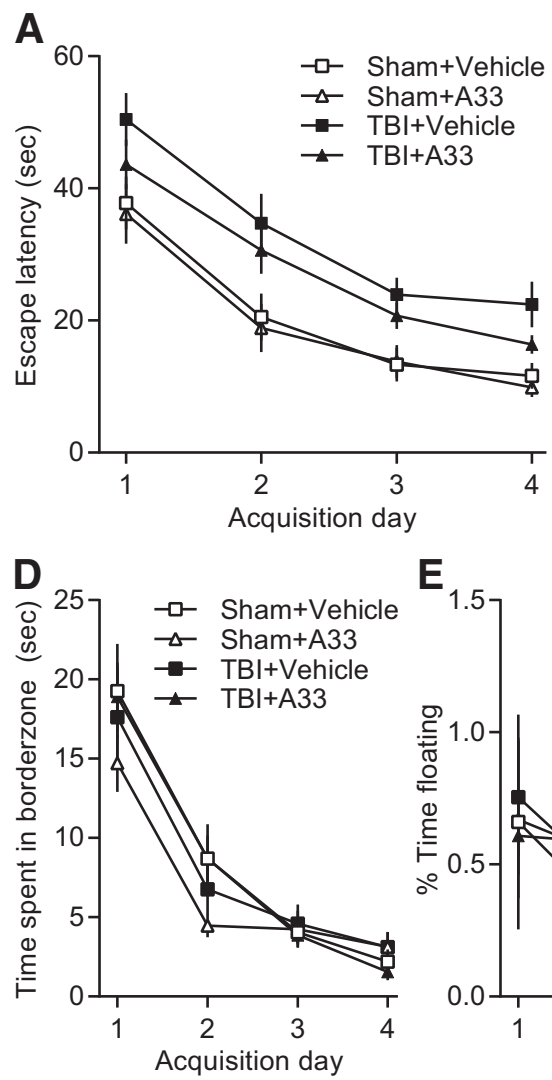

B

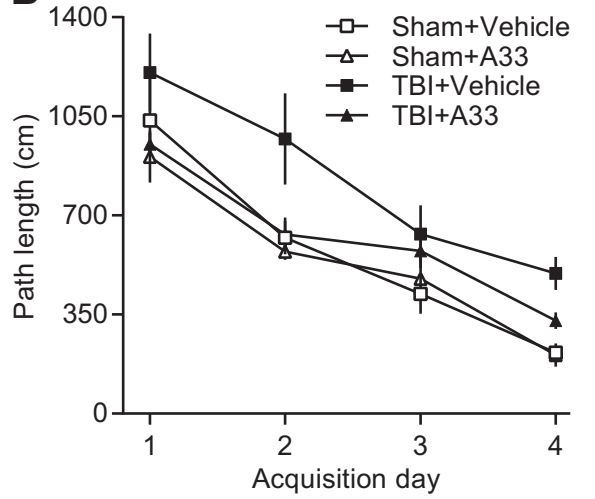

$\mathbf{F}$
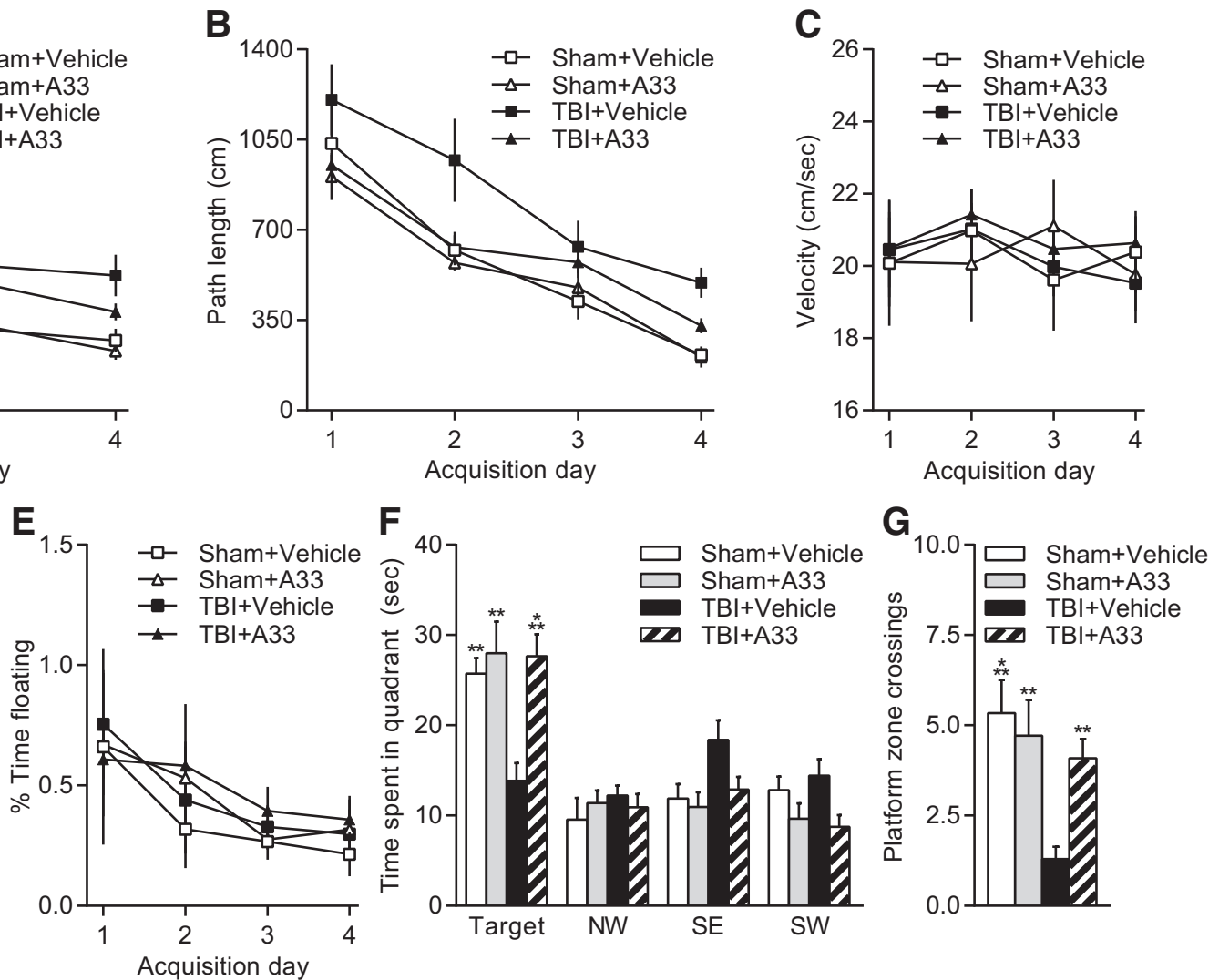

Figure 4. Effects of $A 33$ on acquisition and retention of water maze performance at 3 months after TBI. $\boldsymbol{A}$, Escape latency during water maze acquisition was significantly longer in TBI animals compared with sham animals ( $p<0.001$ ). There was no significant effect of drug treatment. $\boldsymbol{B}$, Path length to reach the hidden platform during water maze acquisition at 3 months postsurgery. TBI animals had significantly longer path lengths to find the hidden platform compared with sham animals $(p<0.001)$. A significant effect of drug treatment was also observed ( $p=0.011)$, and there was no significant interaction of surgery $\times$ drug treatment. $C$, There were no significant differences in swim velocity between sham and TBI animals or drug treatment groups during acquisition. $\boldsymbol{D}$, Thigmotaxis was not significantly different between sham and TBI animals or drug treatment groups. $\boldsymbol{E}$, Percentage time floating during acquisition was not significantly different between TBI and sham animals or drug treatment groups. $\boldsymbol{F}$, Probe trial performance was assessed at $24 \mathrm{~h}$ after the final acquisition day. TBI + vehicle animals spent less time in the target quadrant compared with sham animals treated with vehicle or A33 or TBI+A33 animals. G, Platform zone crossings during the probe trial. TBI+ vehicle animals crossed the platform zone significantly less than Sham + vehicle, Sham +A33, and TBI+A33 treated animals. Sham + vehicle: $n=6$; Sham + A33: $n=7 ;$ TBI+vehicle: $n=10 ;$ TBI+A33: $n=11 ;{ }^{* *} p<0.01,{ }^{* *} p<0.001$ versus $\mathrm{TBI}+$ vehicle animals; two-way ANOVA with Tukey's HSD correction for multiple comparisons.

modality, we modified the water maze to assess spatial working memory at 14 weeks postsurgery by training the animals to locate a hidden platform that remains invariant only between pairs of trials separated by $5 \mathrm{~s}$ (Fig. 5; Hoskison et al., 2009). A three-way ANOVA did not indicate a significant interaction of surgery $X$ drug treatment $\times$ trial. There was a main effect of surgery $\left(F_{(1,60)}=7.66, p=0.007\right)$, drug treatment $\left(F_{(1,60)}=6.69, p=\right.$ $0.012)$, and as expected, trial $\left(F_{(1,60)}=20.55, p<0.001\right)$. These results indicate that $\mathrm{A} 33$ treatment improves working memory in both sham and TBI animals.

A characteristic of chronic TBI is progressive atrophy and the hippocampus is a highly vulnerable structure (Bigler et al., 2002; Serra-Grabulosa et al., 2005). To assess atrophy, at the completion of behavioral testing, we measured cortical and hippocampal volume (Fig. 6). Significant cortical atrophy (Fig. 6A, B) was observed in TBI animals (main effect of surgery $F_{(1,30)}=116.94, p<$ 0.001 ) and there was no effect of A33 treatment. A main effect of surgery $\left(F_{(1,30)}=13.49, p<0.001\right)$, but not drug treatment $\left(F_{(1,30)}=3.69, p=0.064\right)$ was also found with hippocampal atrophy (Fig. 6C), and there was no significant interaction of surgery $\times$ drug treatment $\left(F_{(1,30)}=3.19, p=0.084\right)$. These results indicate that intermittent A33 treatment did not improve pathology in the chronic TBI recovery period.

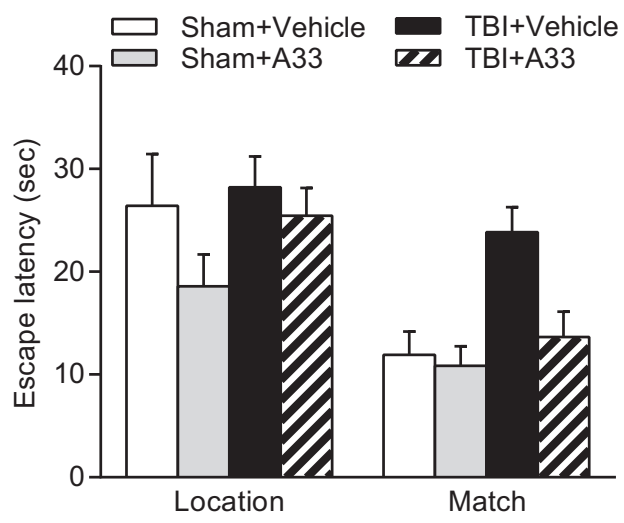

Figure 5. Spatial working memory. There was no significant interaction between surgery $x$ drug treatment $X$ trial. TBl animals had significantly longer escape latencies compared with sham animals $(p=0.007)$, and A33 treatment improved working memory in both sham and TBI animals ( $p=0.012$ ). Sham + vehicle: $n=6$; Sham +A33: $n=7$; TBI + vehicle: $n=10$; $\mathrm{TBI}+\mathrm{A} 33: n=11$; three-way ANOVA with Tukey's HSD correction for multiple comparisons.

Microglia, which are known to remain persistently activated after TBI, were quantified using Iba-1 immunostaining and stereological methods in the ipsilateral parietal cortex and hippocampus (Fig. 7; Acosta et al., 2013; Smith et al., 2013; 
A
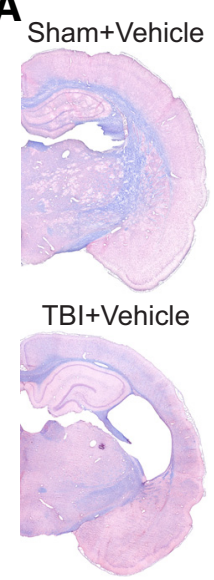

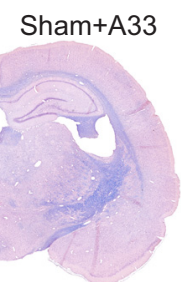

$\mathrm{TBI}+\mathrm{A} 33$

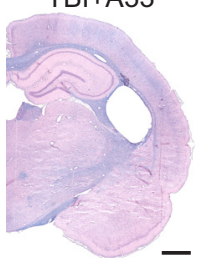

B

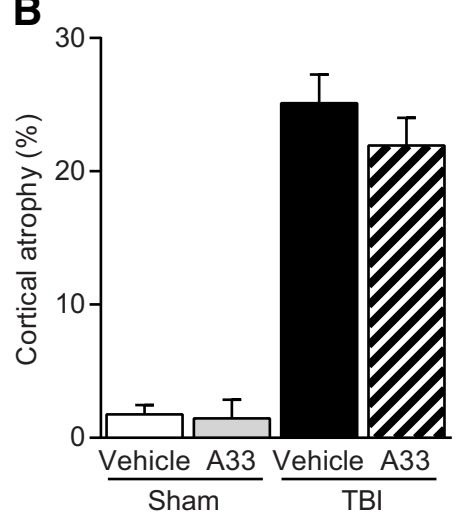

C

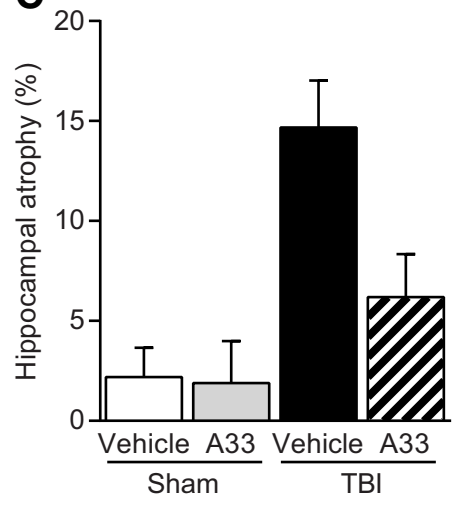

Figure 6. Cortical and hippocampal atrophy at 5 months postsurgery. $\boldsymbol{A}$, Representative sections stained with hematoxylin and eosin plus Luxol fast blue at bregma level $-3.0 \mathrm{~mm}$. Scale bar, 1 mm. $\boldsymbol{B}$, Cortical atrophy. $\boldsymbol{C}$, Hippocampal atrophy. Significant cortical $(p<0.001)$ and hippocampal atrophy $(p<0.001)$ were observed in TBI animals treated with vehicle or A33. No significant main effect of drug treatment or interaction of surgery $\times$ drug treatment were observed. Sham + vehicle: $n=6 ;$ Sham + A33: $n=7 ; \mathrm{TBI}+$ vehicle: $n=10 ; \mathrm{TBI}+\mathrm{A} 33 n=11 ; \mathrm{tw0}$-way ANOVA with Tukey's HSD correction for multiple comparisons.

Glushakova et al., 2014; Kabadi et al., 2014; Loane et al., 2014). There was a significant increase in total Iba-1-positive cell counts at 5 months post-TBI in both the ipsilateral parietal cortex (Fig. $7 A, B, D-F$; main effect of surgery at bregma $-3.3 \mathrm{~mm}: F_{(1,27)}=$ $6.19, p=0.019$ ) and hippocampus (Fig. 7C,G-I; main effect of surgery at bregma $-3.3 \mathrm{~mm}: F_{(1,27)}=35.58, p<0.001$; main effect of surgery at bregma $-4.3 \mathrm{~mm}: F_{(1,27)}=38.33, p<0.001$; main effect of surgery at bregma $-5.3 \mathrm{~mm}: F_{(1,27)}=50.50, p<$ 0.001 ) in TBI animals compared with sham animals. There was no significant effect of drug treatment or interaction of surgery $X$ drug treatment for total Iba-1-positive cells in either the ipsilateral parietal cortex or hippocampus. When differentiated by morphology as ramified, intermediate or ameboid, there was a shift from ramified morphology in sham animals to more intermediate and ameboid cell types in the ipsilateral parietal cortex of TBI animals, and there was no effect of drug treatment or interaction of surgery $\times$ drug treatment (Fig. $7 D-F)$. Ramified Iba-1positive cells were decreased in the ipsilateral parietal cortex of TBI animals compared with sham animals (Fig. 7D-F; main effect of surgery at bregma $-3.3 \mathrm{~mm}: F_{(1,27)}=12.51, p=0.001$; main effect of surgery at bregma $-4.3 \mathrm{~mm}: F_{(1,27)}=21.16, p<$ 0.001 ; main effect of surgery at bregma $-5.3 \mathrm{~mm}: F_{(1,27)}=21.39$, $p<0.001)$. In contrast, there was a significant increase in the number of intermediate Iba-1-positive cells in the ipsilateral parietal cortex (Fig. $7 D, F$; main effect of surgery at bregma -3.3 $\mathrm{mm}: F_{(1,27)}=21.12, p<0.001$; main effect of surgery at bregma $\left.-5.3 \mathrm{~mm}: F_{(1,27)}=10.70, p=0.003\right)$. In addition to the increase in intermediate Iba-1-positive cells, there was also an increase in the number of ameboid Iba-1-positive cells in the ipsilateral parietal cortex (Fig. 7D-F; main effect of surgery at bregma -3.3 $\mathrm{mm}: F_{(1,27)}=12.26, p=0.002$; main effect of surgery at bregma $-4.3 \mathrm{~mm}: F_{(1,27)}=6.33, p=0.018$; main effect of surgery at bregma $\left.-5.3 \mathrm{~mm}: F_{(1,27)}=14.65, p<0.001\right)$. Similar morphological shifts were observed in the ipsilateral hippocampus. There was a significant increase in intermediate Iba-1-positive cells in the ipsilateral hippocampus (Fig. 7G-I; main effect of surgery at bregma $-3.3 \mathrm{~mm}: F_{(1,27)}=41.29, p<0.001$; main effect of surgery at bregma $-4.3 \mathrm{~mm}: F_{(1,27)}=47.92, p<0.001$; main effect of surgery at bregma $\left.-5.3 \mathrm{~mm}: F_{(1,27)}=42.66, p<0.001\right)$, as well as ameboid Iba-1-positive cells (Fig. $7 G-I$; main effect of surgery at bregma $-3.3 \mathrm{~mm}: F_{(1,27)}=8.95, p=0.006$; main effect of surgery at bregma $-4.3 \mathrm{~mm}: F_{(1,27)}=8.08, p=0.008$; main effect of surgery at bregma $\left.-5.3 \mathrm{~mm}: F_{(1,27)}=7.62, p=0.010\right)$ in TBI animals compared with sham animals. There was no significant effect of A33 treatment or interaction of surgery $\times$ drug treatment for morphology differentiation of Iba-1-positive cells in the hippocampus. Overall, these results suggest that TBI causes an increase in Iba-1-positive microglia that persists for months after injury, and that treatment with A33 does not significantly alter the number, or morphology of Iba-1-positive microglia.

TBI decreases levels of basal CREB phosphorylation at 3 months postinjury (Atkins et al., 2009). To determine whether A33 can rescue this depression in basal CREB phosphorylation, we treated animals with $\mathrm{A} 33$ or vehicle $(0.3 \mathrm{mg} / \mathrm{kg}$, i.p. $)$ at 3 months postsurgery, and then assayed the ipsilateral hippocampus at 30 min post-treatment by Western blotting for changes in CREB phosphorylation (Fig. 8). TBI resulted in a significant decrease in basal phospho-CREB levels (main effect of surgery: $\left.F_{(1,16)}=17.61, p<0.001\right)$, and this was rescued with A33 treatment (Fig. $8 B$; surgery $\times$ drug treatment interaction: $F_{(1,16)}=$ 4.78, $p=0.044)$. No significant differences in total CREB levels were observed between groups. There was also no significant effect of A33 treatment on phospho-CREB levels in sham animals. These results indicate that TBI results in a depression in phospho-CREB levels that can be elevated with a PDE4B inhibitor.

\section{Discussion}

Over 3 million individuals are living with chronic TBI disabilities and $70-85 \%$ report learning and memory impairments (Lew et al., 2006; Zaloshnja et al., 2008). This is an unmet need with no current effective therapy (Wheaton et al., 2011). Our laboratory has found that TBI results in CREB activation deficits during learning (Titus et al., 2013b). In this study, we determined whether a selective PDE4B inhibitor would improve learning and memory in the chronic phase of TBI. Our data demonstrate that a PDE4B inhibitor has procognitive benefits when administered 3 months postinjury. A33 improved hippocampal LTP, crossed the blood-brain barrier at relevant concentrations and improved performance in several learning tasks.

Targeting PDE4 as a therapeutic for TBI using pan-PDE4 inhibitors has been hampered by significant side effects. Rolipram, 

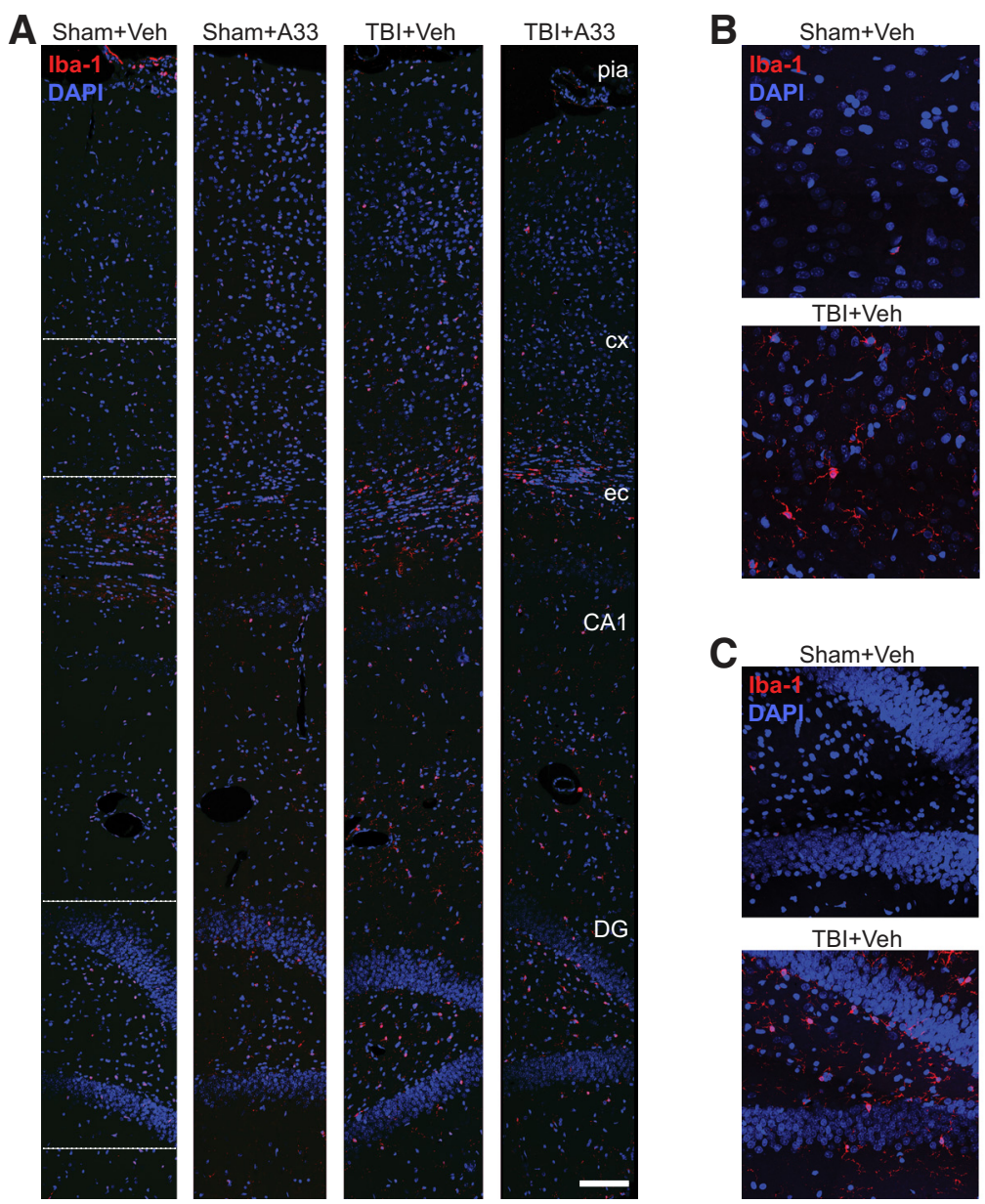

CA1
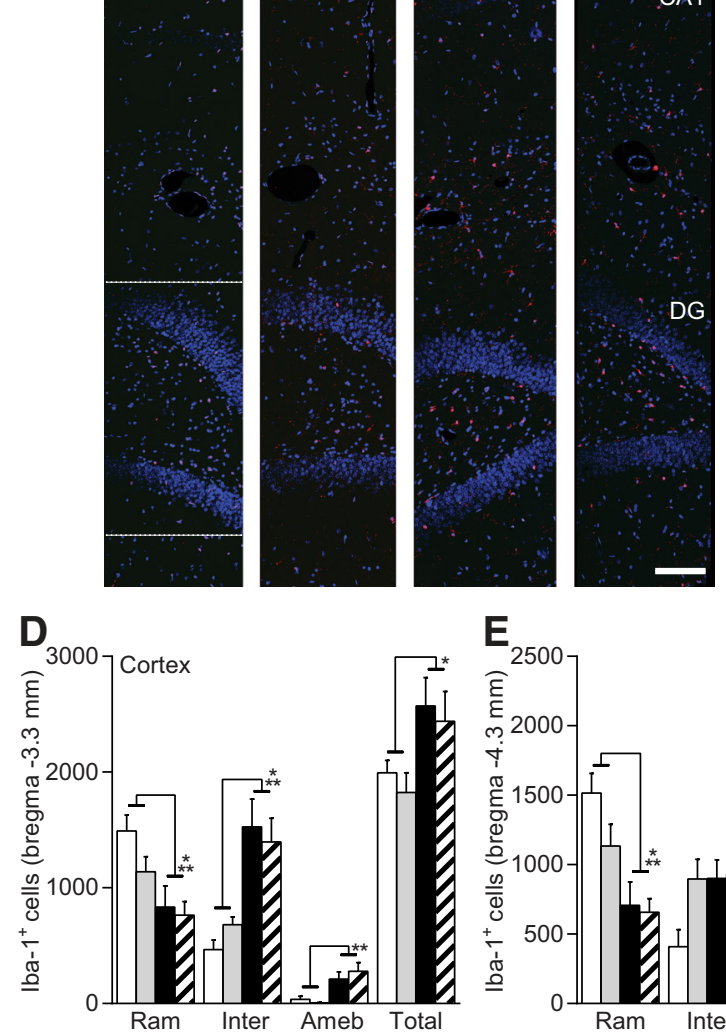

\section{E}
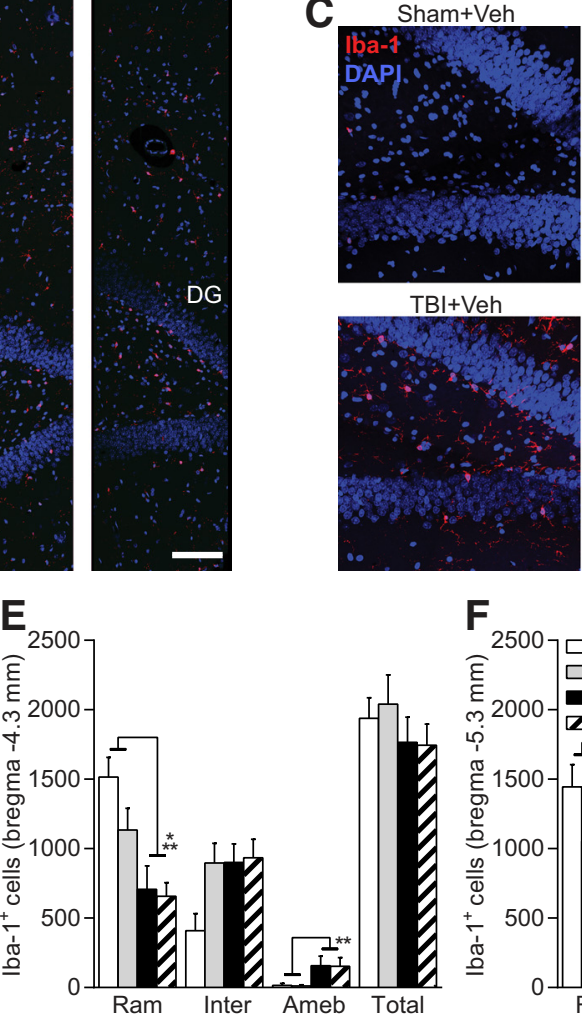

$\mathrm{TBI}+\mathrm{Veh}$

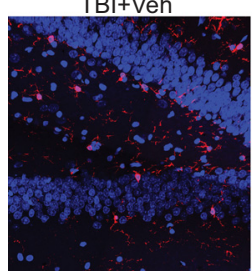

F

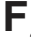

Sham+A33

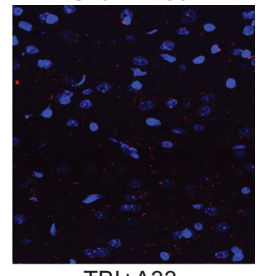

$\mathrm{TB}+\mathrm{A} 33$

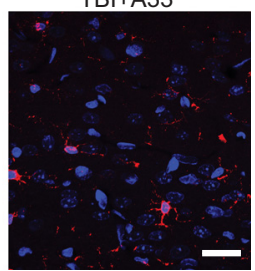

Sham+A33

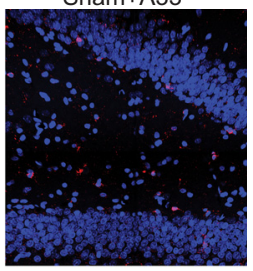

$\mathrm{TBI}+\mathrm{A} 33$

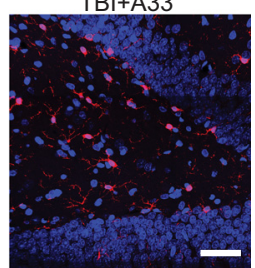

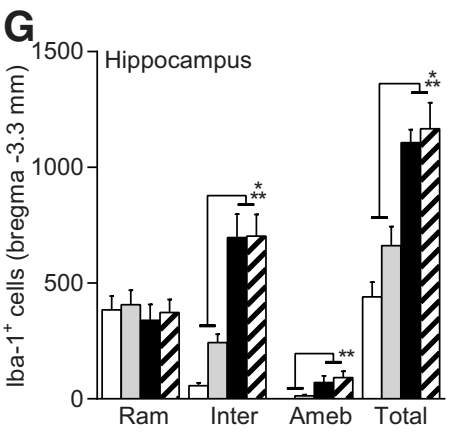

$\mathrm{H}$

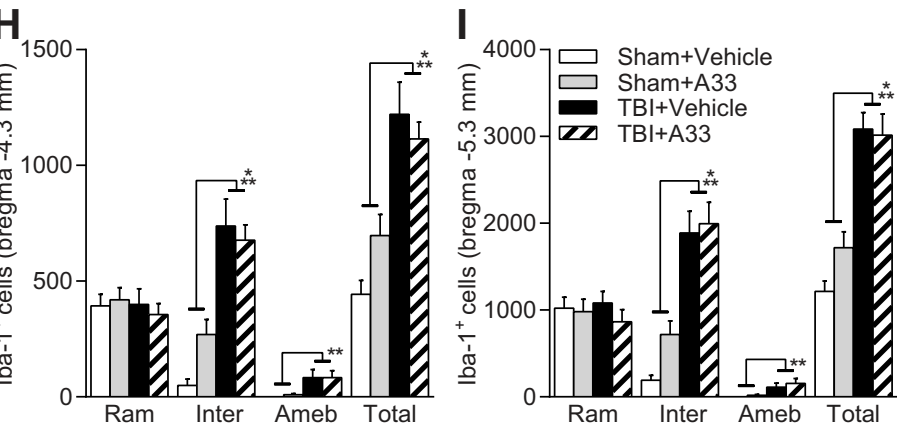

Figure 7. Iba-1-positive cells in the ipsilateral parietal cortex and hippocampus at 5 months postsurgery. $\boldsymbol{A}$, Representative images immunostained with Iba- 1 (red) and counterstained with DAPI (blue) at bregma level $-3.3 \mathrm{~mm}$. Images at $20 \times$ magnification spanning the ipsilateral parietal cortex to the hippocampus (cx, cortex; ec, external capsule; DG, dentate gyrus). Scale bar, 100 $\mu \mathrm{m}$. B, Higher-magnification of the parietal cortex. Scale bar, $25 \mu \mathrm{m}$. C, Higher-magnification of the dentate gyrus. Scale bar, $50 \mu \mathrm{m}$. Quantification of Iba-1-positive cells in the ipsilateral parietal cortex $(\boldsymbol{D}-\boldsymbol{F})$ and hippocampus (G-I) at bregma levels $-3.3,-4.3$, and $-5.3 \mathrm{~mm}$. Iba-1-positive cells were classified as ramified (Ram), intermediate (Inter), or ameboid (Ameb) based on morphology. Sham + vehicle: $n=6 ;$ Sham $+\mathrm{A} 33: n=7 ; \mathrm{TBI}+$ vehicle: $n=7 ; \mathrm{TBI}+\mathrm{A} 33 n=11$. A main effect of surgery was observed, but there was no significant effect of drug treatment or interaction of surgery $\times$ drug treatment. ${ }^{*} p<0.05,{ }^{* *} p<0.01,{ }^{* * *} p<0.001$ Sham versus TBI; two-way ANOVA with Tukey's HSD correction for multiple comparisons. 


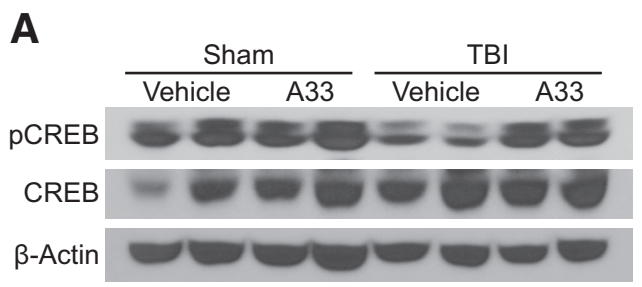

B

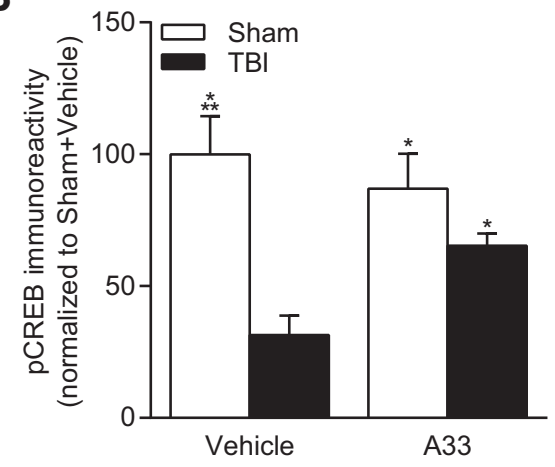

Figure 8. Phosphorylated CREB levels in the ipsilateral hippocampus at 3 months post-TBI. $A$, Representative Western blots of phosphorylated CREB, CREB, and $\beta$-actin. $\boldsymbol{B}$, Densitometric results. Phosphorylated CREB levels were significantly decreased at 3 months post-TBI and were increased with $\mathrm{A} 33$ treatment; $n=5 /$ group. ${ }^{*} p<0.05,{ }^{* * *} p<0.001$ versus TBI+ vehicle; two-way ANOVA with Tukey's HSD correction for multiple comparisons.

a pan-PDE4 inhibitor, improves cognition but contradictorily worsens pathology and produces side effects of nausea and emesis (Robichaud et al., 2001; Atkins et al., 2012; Titus et al., 2013b). PDE4D, but not PDE4B, is linked with emesis (Robichaud et al., 2002; Naganuma et al., 2009; Burgin et al., 2010). In our studies, a relatively low dose of A33 $(0.3 \mathrm{mg} / \mathrm{kg})$ improved cognition, while a much higher dose of $100 \mathrm{mg} / \mathrm{kg}$ was tolerated without emesis (Naganuma et al., 2009).

A33 inhibits all PDE4B isoforms and is 49-fold more selective toward PDE4B compared with PDE4D, and does not appreciably inhibit other PDEs (Naganuma et al., 2009; Fox et al., 2014). Contrary to our previous studies demonstrating that PDE4B2 was significantly upregulated between $30 \mathrm{~min}$ to $24 \mathrm{~h}$ post-TBI, at 3 months after TBI, PDE4B isoforms were present but not upregulated above sham levels (Oliva et al., 2012; Wilson et al., 2016). To evaluate the feasibility of A33 for inhibiting PDE4B in the injured brain, we measured brain concentrations of $A 33$ at the dose used for behavior assessment. A33 achieved brain concentrations 4- to 5-fold higher than the PDE4B $\mathrm{IC}_{50}$ and at least tenfold less than the $\mathrm{IC}_{50}$ of other PDEs (Fox et al., 2014). However, a caveat is that the animals were not perfused before analysis, thus both blood and brain tissue were measured. A33 B/P was low in both sham and TBI animals, which was expected since A33 is a P-glycoprotein substrate as shown by MDR1-MDCK cell transport studies (efflux ratio $=14.4$, M.E.G. unpublished data). Current studies are underway to improve the pharmacokinetic properties of A33.

A33 is a reversible inhibitor of PDE4B (Fox et al., 2014). It was not possible to directly measure inhibition of PDE4B in the brain after A33 treatment because methods to isolate PDE4B from other PDE4 isoforms in brain homogenates would dilute the inhibitor (Clapcote et al., 2007). As a surrogate to assaying PDE4B inhibition, we measured TNF- $\alpha$ levels to assess whether A33 inhibits a pathway known to be regulated by PDE4B (Jin et al., 2005). We chose TNF- $\alpha$ because inflammatory cells from
PDE4B, but not PDE4A or PDE4D, knock-out mice have reduced TNF- $\alpha$ levels in response to inflammatory stimuli (Jin and Conti, 2002; Jin et al., 2005). TBI stimulates TNF- $\alpha$ and PDE4B2 expression within $30 \mathrm{~min}$ after injury which lasts for up to $24 \mathrm{~h}$ (Vitarbo et al., 2004; Oliva et al., 2012), although a few studies have observed increased levels of TNF- $\alpha$ at 1-7 d post-TBI (Su et al., 2014; Tsai et al., 2015). In accordance with previous studies, we did not detect measurable levels of TNF- $\alpha$ by ELISA at 3 months postsurgery (Yakovlev and Faden, 1994; Knoblach et al., 1999). Therefore, we assessed TNF- $\alpha$ levels at $6 \mathrm{~h}$ postsurgery and found that A33 significantly reduced TNF- $\alpha$ acutely after TBI, suggesting that an inflammatory pathway mediated by PDE4B is inhibited with A33 (Jin and Conti, 2002; Jin et al., 2005). However, this result does not demonstrate that A33 selectively targeted PDE4B in vivo and a limitation of this study is whether brain-specific inhibition of PDE4B was the mechanism for the cognitive improvements was not directly determined.

PDE4 knock-out mice and mice with a mutation in the catalytic domain of PDE4B have distinctive behavioral phenotypes. $P d e 4 b^{-1-}$ mice have no observable phenotype in hippocampal LTP and standard learning and memory measures (Siuciak et al., 2008; Zhang et al., 2008; Rutten et al., 2011). In contrast, Pde $4 d^{-1-}$ mice have enhanced LTP and hippocampal-dependent memory (Rutten et al., 2008; Li et al., 2011; Schaefer et al., 2012). Like $P d e 4 b^{-1-}$ mice, $P d e 4 a^{-/-}$mice do not have enhanced learning, and both $P d e 4 a^{-1-}$ and $P d e 4 b^{-1-}$ mice have increased anxiety (Zhang et al., 2008; Hansen et al., 2014). Mice with a mutation in the catalytic domain of PDE4B (PDE4B ${ }^{\mathrm{Y} 358 \mathrm{C} / \mathrm{Y} 358 \mathrm{C}}$ ) have reduced anxiety (McGirr et al., 2016). In this study, A33 administration did not alter baseline freezing during fear conditioning, or increase thigmotaxis in the water maze, suggesting that the improvement in fear conditioning with A33 may not be due to increased anxiogenic behavior. However, further experiments are required to definitively determine whether A33 alters anxiety levels. The behavioral differences between $P d e 4 b^{-1-}$ mice, $\mathrm{PDE} 4 \mathrm{~B}^{\mathrm{Y} 358 \mathrm{C} / \mathrm{Y} 358 \mathrm{C}}$ mice, and $\mathrm{A} 33$-treated rats may be due to differences in the assessment of a developmental manipulation of PDE4B versus acute inhibition, as well as interaction with the injured brain. Given that we did not observe any significant effects of A33 on learning and memory in sham animals with the exception of spatial working memory, this suggests that TBI induces hippocampal-dependent LTP and learning deficits that are improved with a PDE4B-selective inhibitor. However, whether the improvements in learning and memory are directly mediated by improvements in hippocampal synaptic plasticity remains to be causally established.

In the hippocampus, $\mathrm{PDE} 4 \mathrm{~B}$ protein expression is restricted to the dentate gyrus, although PDE4B mRNA is also found in areas CA1 and CA3 (Cherry and Davis, 1999; Pérez-Torres et al., 2000; Reyes-Irisarri et al., 2008; Lakics et al., 2010; Johansson et al., 2012). However, other studies indicate that PDE4B is involved in synaptic plasticity in other subregions of the hippocampus beyond the dentate gyrus. $P d e 4 b^{-1-}$ mice have enhanced basal synaptic transmission in area CA1 (Rutten et al., 2011). PDE4B3 transcription is upregulated in area CA1 after LTP induction (Ahmed and Frey, 2005). Additionally, LTD in area CA1 is enhanced in $P d e 4 b^{-1-}$ mice, although unaltered in PDE4B ${ }^{\mathrm{Y} 358 \mathrm{C} / \mathrm{Y} 358 \mathrm{C}}$ mice (Rutten et al., 2011; McGirr et al., 2016). Reversal learning in the water maze is impaired in $P d e 4 b^{-/-}$mice, but enhanced in PDE4B ${ }^{\mathrm{Y} 358 \mathrm{C} / \mathrm{Y} 358 \mathrm{C}}$ mice (Rutten et al., 2011; McGirr et al., 2016). These results suggest that LTD and cognitive flexibility are potential outcome measures to investigate with A33 treatment. 
The underlying mechanism for the improvements in learning and memory after TBI with A33 is currently unknown. The animals received eight doses of A33 between 3 and 4 months postsurgery. The half-life of A33 in the brain is 3.8-4.5 h in mice (M.E.G., unpublished data), suggesting that the drug may have been active for a reasonable duration to alter mechanisms in addition to synaptic plasticity. One potential mechanism may be hippocampal neurogenesis. Both $P d e 4 b^{-1-}$ and PDE4B ${ }^{\mathrm{Y} 358 \mathrm{C} / \mathrm{Y3} 38 \mathrm{C}}$ mice have increased adult neurogenesis in the dentate gyrus (Zhang et al., 2008; McGirr et al., 2016). TBI increases neurogenesis transiently, which is then chronically reduced and may have been altered with A33 (Dash et al., 2001; Urrea et al., 2007; Potts et al., 2009; Atkins et al., 2010). Another potential mechanism mediated by A33 is chronic inflammation. PDE4B regulates proinflammatory cytokine expression in microglia and macrophages and activated microglia are increased within the brain for months after trauma (Acosta et al., 2013; Loane et al., 2014). However, microglia numbers were not significantly altered by A33. Furthermore, we did not detect measurable levels of TNF- $\alpha$ in either the cortex or hippocampus at 3 months postinjury. Studies to determine whether A33 impacts neurogenesis or other inflammatory mechanisms may yield insights into the processes involved in the cognitive improvements with A33 treatment.

Currently, there are several clinical trials to improve longterm cognitive impairments after TBI. Hyperbaric oxygen, amantadine, amino acid supplementation, methylphenidate, sildenafil, citicoline, and aerobic exercise are among the therapeutics being investigated in chronic TBI patients (Wheaton et al., 2009; McDonnell et al., 2011). There are also several clinical trials testing cognitive rehabilitation and the combination of rehabilitation with a pharmacological cognitive enhancer, such as a PDE4B inhibitor, may ultimately be the optimal strategy (Cicerone et al., 2000; Rohling et al., 2009). As with the cholinesterase inhibitors used for the treatment of Alzheimer's disease, which address cholinergic hypofunction, treatment with a PDE4B inhibitor may address hypofunction in signaling pathways using CREB phosphorylation.

Use of PDE4 inhibitors to improve cognitive impairments due to aging or injury is a promising therapeutic route. There are several PDE inhibitors in clinical trials to improve cognition in healthy aging adults, as well as Alzheimer's disease and mild cognitive impairment (García-Osta et al., 2012; Sakurai et al., 2013; Schwam et al., 2014; Shim et al., 2014). This study demonstrates that short-term treatment with a PDE4B inhibitor improves synaptic plasticity, and learning and memory when delivered at the time of learning at 3 months after TBI. These findings support the approach of targeting subtype-selective PDE4B inhibition to restore cognitive function during the chronic recovery phase of TBI.

\section{References}

Acosta SA, Tajiri N, Shinozuka K, Ishikawa H, Grimmig B, Diamond D, Sanberg PR, Bickford PC, Kaneko Y, Borlongan CV (2013) Long-term upregulation of inflammation and suppression of cell proliferation in the brain of adult rats exposed to traumatic brain injury using the controlled cortical impact model. PLoS One 8:e53376. CrossRef Medline

Ahmed T, Frey JU (2005) Phosphodiesterase 4B (PDE4B) and cAMP-level regulation within different tissue fractions of rat hippocampal slices during long-term potentiation in vitro. Brain Res 1041:212-222. CrossRef Medline

Ashkenazi A (2002) Targeting death and decoy receptors of the tumournecrosis factor superfamily. Nat Rev Cancer 2:420-430. CrossRef Medline

Atkins CM, Oliva AA Jr, Alonso OF, Pearse DD, Bramlett HM, Dietrich WD
(2007) Modulation of the cAMP signaling pathway after traumatic brain injury. Exp Neurol 208:145-158. CrossRef Medline

Atkins CM, Falo MC, Alonso OF, Bramlett HM, Dietrich WD (2009) Deficits in ERK and CREB activation in the hippocampus after traumatic brain injury. Neurosci Lett 459:52-56. CrossRef Medline

Atkins CM, Truettner JS, Lotocki G, Sanchez-Molano J, Kang Y, Alonso OF, Sick TJ, Dietrich WD, Bramlett HM (2010) Post-traumatic seizure susceptibility is attenuated by hypothermia therapy. Eur J Neurosci 32:19121920. CrossRef Medline

Atkins CM, Kang Y, Furones C, Truettner JS, Alonso OF, Dietrich WD (2012) Postinjury treatment with rolipram increases hemorrhage after traumatic brain injury. J Neurosci Res 90:1861-1871. CrossRef Medline

Atkins CM, Cepero ML, Kang Y, Liebl DJ, Dietrich WD (2013) Effects of early rolipram treatment on histopathological outcome after controlled cortical impact injury in mice. Neurosci Lett 532:1-6. CrossRef Medline

Bigler ED, Anderson CV, Blatter DD (2002) Temporal lobe morphology in normal aging and traumatic brain injury. Am J Neuroradiol 23:255-266. Medline

Burgin AB, Magnusson OT, Singh J, Witte P, Staker BL, Bjornsson JM, Thorsteinsdottir M, Hrafnsdottir S, Hagen T, Kiselyov AS, Stewart LJ, Gurney ME (2010) Design of phosphodiesterase 4D (PDE4D) allosteric modulators for enhancing cognition with improved safety. Nat Biotechnol 28: 63-70. CrossRef Medline

Cherry JA, Davis RL (1999) Cyclic AMP phosphodiesterases are localized in regions of the mouse brain associated with reinforcement, movement, and affect. J Comp Neurol 407:287-301. CrossRef Medline

Cicerone KD, Dahlberg C, Kalmar K, Langenbahn DM, Malec JF, Bergquist TF, Felicetti T, Giacino JT, Harley JP, Harrington DE, Herzog J, Kneipp S, Laatsch L, Morse PA (2000) Evidence-based cognitive rehabilitation: recommendations for clinical practice. Arch Phys Med Rehabil 81: 1596-1615. CrossRef Medline

Clapcote SJ, Lipina TV, Millar JK, Mackie S, Christie S, Ogawa F, Lerch JP, Trimble K, Uchiyama M, Sakuraba Y, Kaneda H, Shiroishi T, Houslay MD, Henkelman RM, Sled JG, Gondo Y, Porteous DJ, Roder JC (2007) Behavioral phenotypes of Discl missense mutations in mice. Neuron 54:387-402. CrossRef Medline

Dash PK, Mach SA, Moore AN (2001) Enhanced neurogenesis in the rodent hippocampus following traumatic brain injury. J Neurosci Res 63:313319. CrossRef Medline

Fan L, Young PR, Barone FC, Feuerstein GZ, Smith DH, McIntosh TK (1996) Experimental brain injury induces differential expression of tumor necrosis factor- $\alpha$ mRNA in the CNS. Brain Res Mol Brain Res 36: 287-291. CrossRef Medline

Faul M, Xu L, Wald MM, Coronado VG (2010) Traumatic brain injury in the United States: emergency department visits, hospitalizations and deaths. Centers for Disease Control and Prevention, National Center for Injury Prevention and Control, Atlanta, GA.

Ferreira AP, Rodrigues FS, Della-Pace ID, Mota BC, Oliveira SM, Velho Gewehr Cde C, Bobinski F, de Oliveira CV, Brum JS, Oliveira MS, Furian AF, de Barros CS, Ferreira J, Santos AR, Fighera MR, Royes LF (2013) The effect of NADPH-oxidase inhibitor apocynin on cognitive impairment induced by moderate lateral fluid percussion injury: role of inflammatory and oxidative brain damage. Neurochem Int 63:583-593. CrossRef Medline

Fox D 3rd, Burgin AB, Gurney ME (2014) Structural basis for the design of selective phosphodiesterase 4B inhibitors. Cell Signal 26:657-663. CrossRef Medline

García-Osta A, Cuadrado-Tejedor M, García-Barroso C, Oyarzábal J, Franco R (2012) Phosphodiesterases as therapeutic targets for Alzheimer's disease. ACS Chem Neurosci 3:832-844. CrossRef Medline

Glushakova OY, Johnson D, Hayes RL (2014) Delayed increases in microvascular pathology after experimental traumatic brain injury are associated with prolonged inflammation, blood-brain barrier disruption, and progressive white matter damage. J Neurotrauma 31:1180-1193. CrossRef Medline

Hansen RT 3rd, Conti M, Zhang HT (2014) Mice deficient in phosphodiesterase-4A display anxiogenic-like behavior. Psychopharmacology 231:2941-2954. CrossRef Medline

Hoskison MM, Moore AN, Hu B, Orsi S, Kobori N, Dash PK (2009) Persistent working memory dysfunction following traumatic brain injury: evidence for a time-dependent mechanism. Neuroscience 159:483-491. CrossRef Medline 
Houslay MD, Schafer P, Zhang KY (2005) Keynote review: phosphodiesterase-4 as a therapeutic target. Drug Discov Today 10:1503-1519. CrossRef Medline

Jin SL, Conti M (2002) Induction of the cyclic nucleotide phosphodiesterase PDE4B is essential for LPS-activated TNF- $\alpha$ responses. Proc Natl Acad Sci U S A 99:7628-7633. CrossRef Medline

Jin SL, Lan L, Zoudilova M, Conti M (2005) Specific role of phosphodiesterase $4 \mathrm{~B}$ in lipopolysaccharide-induced signaling in mouse macrophages. J Immunol 175:1523-1531. CrossRef Medline

Johansson EM, Reyes-Irisarri E, Mengod G (2012) Comparison of cAMPspecific phosphodiesterase mRNAs distribution in mouse and rat brain. Neurosci Lett 525:1-6. CrossRef Medline

Kabadi SV, Stoica BA, Loane DJ, Luo T, Faden AI (2014) CR8, a novel inhibitor of CDK, limits microglial activation, astrocytosis, neuronal loss, and neurologic dysfunction after experimental traumatic brain injury. J Cereb Blood Flow Metab 34:502-513. CrossRef Medline

Klann E, Roberson ED, Knapp LT, Sweatt JD (1998) A role for superoxide in protein kinase $\mathrm{C}$ activation and induction of long-term potentiation. J Biol Chem 273:4516-4522. CrossRef Medline

Knoblach SM, Fan L, Faden AI (1999) Early neuronal expression of tumor necrosis factor- $\alpha$ after experimental brain injury contributes to neurological impairment. J Neuroimmunol 95:115-125. CrossRef Medline

Lakics V, Karran EH, Boess FG (2010) Quantitative comparison of phosphodiesterase mRNA distribution in human brain and peripheral tissues. Neuropharmacology 59:367-374. CrossRef Medline

Lew HL, Poole JH, Guillory SB, Salerno RM, Leskin G, Sigford B (2006) Persistent problems after traumatic brain injury: the need for long-term follow-up and coordinated care. J Rehabil Res Dev 43:vii-x. Medline

Li YF, Cheng YF, Huang Y, Conti M, Wilson SP, O’Donnell JM, Zhang HT (2011) Phosphodiesterase-4D knock-out and RNA interferencemediated knock-down enhance memory and increase hippocampal neurogenesis via increased cAMP signaling. J Neurosci 31:172-183. CrossRef Medline

Loane DJ, Kumar A, Stoica BA, Cabatbat R, Faden AI (2014) Progressive neurodegeneration after experimental brain trauma: association with chronic microglial activation. J Neuropathol Exp Neurol 73:14-29. CrossRef Medline

Lotocki G, de Rivero Vaccari JP, Perez ER, Alonso OF, Curbelo K, Keane RW, Dietrich WD (2006) Therapeutic hypothermia modulates TNFR1 signaling in the traumatized brain via early transient activation of the JNK pathway and suppression of XIAP cleavage. Eur J Neurosci 24:2283-2290. CrossRef Medline

McAllister TW, Flashman LA, McDonald BC, Saykin AJ (2006) Mechanisms of working memory dysfunction after mild and moderate TBI: evidence from functional MRI and neurogenetics. J Neurotrauma 23: 1450-1467. CrossRef Medline

McConeghy KW, Hatton J, Hughes L, Cook AM (2012) A review of neuroprotection pharmacology and therapies in patients with acute traumatic brain injury. CNS Drugs 26:613-636. CrossRef Medline

McDonnell MN, Smith AE, Mackintosh SF (2011) Aerobic exercise to improve cognitive function in adults with neurological disorders: a systematic review. Arch Phys Med Rehabil 92:1044-1052. CrossRef Medline

McGirr A, Lipina TV, Mun HS, Georgiou J, Al-Amri AH, Ng E, Zhai D, Elliott C, Cameron RT, Mullins JG, Liu F, Baillie GS, Clapcote SJ, Roder JC (2016) Specific inhibition of phosphodiesterase-4B results in anxiolysis and facilitates memory acquisition. Neuropsychopharmacology 41: 1080-1092. CrossRef Medline

Naganuma K, Omura A, Maekawara N, Saitoh M, Ohkawa N, Kubota T, Nagumo H, Kodama T, Takemura M, Ohtsuka Y, Nakamura J, Tsujita R, Kawasaki K, Yokoi H, Kawanishi M (2009) Discovery of selective PDE4B inhibitors. Bioorg Med Chem Lett 19:3174-3176. CrossRef Medline

Oliva AA Jr, Kang Y, Furones C, Alonso OF, Bruno O, Dietrich WD, Atkins CM (2012) Phosphodiesterase isoform-specific expression induced by traumatic brain injury. J Neurochem 123:1019-1029. CrossRef Medline

Pérez-Torres S, Miró X, Palacios JM, Cortés R, Puigdoménech P, Mengod G (2000) Phosphodiesterase type 4 isozymes expression in human brain examined by in situ hybridization histochemistry and $\left[{ }^{3} \mathrm{H}\right]$ rolipram binding autoradiography. Comparison with monkey and rat brain. J Chem Neuroanat 20:349-374. CrossRef Medline

Potts MB, Rola R, Claus CP, Ferriero DM, Fike JR, Noble-Haeusslein LJ (2009) Glutathione peroxidase overexpression does not rescue impaired neurogenesis in the injured immature brain. J Neurosci Res 87:18481857. CrossRef Medline

Press NJ, Banner KH (2009) PDE4 inhibitors: a review of the current field. Prog Med Chem 47:37-74. CrossRef Medline

Reyes-Irisarri E, Pérez-Torres S, Miró X, Martínez E, Puigdomènech P, Palacios JM, Mengod G (2008) Differential distribution of PDE4B splice variant mRNAs in rat brain and the effects of systemic administration of LPS in their expression. Synapse 62:74-79. CrossRef Medline

Robichaud A, Savoie C, Stamatiou PB, Tattersall FD, Chan CC (2001) PDE4 inhibitors induce emesis in ferrets via a noradrenergic pathway. Neuropharmacology 40:262-269. CrossRef Medline

Robichaud A, Savoie C, Stamatiou PB, Lachance N, Jolicoeur P, Rasori R, Chan CC (2002) Assessing the emetic potential of PDE4 inhibitors in rats. Br J Pharmacol 135:113-118. CrossRef Medline

Rohling ML, Faust ME, Beverly B, Demakis G (2009) Effectiveness of cognitive rehabilitation following acquired brain injury: a meta-analytic reexamination of Cicerone et al.'s $(2000,2005)$ systematic reviews. Neuropsychology 23:20-39. CrossRef Medline

Rudy JW, O'Reilly RC (1999) Contextual fear conditioning, conjunctive representations, pattern completion, and the hippocampus. Behav Neurosci 113:867-880. CrossRef Medline

Rutten K, Misner DL, Works M, Blokland A, Novak TJ, Santarelli L, Wallace TL (2008) Enhanced long-term potentiation and impaired learning in phosphodiesterase $4 \mathrm{D}$-knockout $\left(P D E 4 D^{-1-}\right)$ mice. Eur J Neurosci 28: 625-632. CrossRef Medline

Rutten K, Wallace TL, Works M, Prickaerts J, Blokland A, Novak TJ, Santarelli L, Misner DL (2011) Enhanced long-term depression and impaired reversal learning in phosphodiesterase $4 \mathrm{~B}$-knockout $\left(P D E 4 B^{-1-}\right)$ mice. Neuropharmacology 61:138-147. CrossRef Medline

Sakurai H, Hanyu H, Sato T, Kume K, Hirao K, Kanetaka H, Iwamoto T (2013) Effects of cilostazol on cognition and regional cerebral blood flow in patients with Alzheimer's disease and cerebrovascular disease: a pilot study. Geriatr Gerontol Int 13:90-97. CrossRef Medline

Schaefer TL, Braun AA, Amos-Kroohs RM, Williams MT, Ostertag E, Vorhees CV (2012) A new model of Pde4d deficiency: genetic knockdown of PDE4D enzyme in rats produces an antidepressant phenotype without spatial cognitive effects. Genes Brain Behav 11:614-622. CrossRef Medline

Schwam EM, Nicholas T, Chew R, Billing CB, Davidson W, Ambrose D, Altstiel LD (2014) A multicenter, double-blind, placebo-controlled trial of the PDE9A inhibitor, PF-04447943, in Alzheimer's disease. Curr Alzheimer Res 11:413-421. CrossRef Medline

Serra-Grabulosa JM, Junqué C, Verger K, Salgado-Pineda P, Mañeru C, Mercader JM (2005) Cerebral correlates of declarative memory dysfunctions in early traumatic brain injury. J Neurol Neurosurg Psychiatry 76: 129-131. CrossRef Medline

Shim YS, Pae CU, Cho KJ, Kim SW, Kim JC, Koh JS (2014) Effects of daily low-dose treatment with phosphodiesterase type 5 inhibitor on cognition, depression, somatization and erectile function in patients with erectile dysfunction: a double-blind, placebo-controlled study. Int J Impot Res 26:76-80. CrossRef Medline

Shojo H, Kaneko Y, Mabuchi T, Kibayashi K, Adachi N, Borlongan CV (2010) Genetic and histologic evidence implicates role of inflammation in traumatic brain injury-induced apoptosis in the rat cerebral cortex following moderate fluid percussion injury. Neuroscience 171:12731282. CrossRef Medline

Siuciak JA, McCarthy SA, Chapin DS, Martin AN (2008) Behavioral and neurochemical characterization of mice deficient in the phosphodiesterase-4B (PDE4B) enzyme. Psychopharmacology 197:115-126. CrossRef Medline

Smith C, Gentleman SM, Leclercq PD, Murray LS, Griffin WS, Graham DI, Nicoll JA (2013) The neuroinflammatory response in humans after traumatic brain injury. Neuropathol Appl Neurobiol 39:654-666. CrossRef Medline

Su Y, Fan W, Ma Z, Wen X, Wang W, Wu Q, Huang H (2014) Taurine improves functional and histological outcomes and reduces inflammation in traumatic brain injury. Neuroscience 266:56-65. CrossRef Medline

Taupin V, Toulmond S, Serrano A, Benavides J, Zavala F (1993) Increase in IL-6, IL-1 and TNF levels in rat brain following traumatic lesion. Influence of pre- and post-traumatic treatment with Ro5 4864, a peripheraltype (p site) benzodiazepine ligand. J Neuroimmunol 42:177-185. CrossRef Medline 
Thurman DJ, Alverson C, Dunn KA, Guerrero J, Sniezek JE (1999) Traumatic brain injury in the United States: a public health perspective. J Head Trauma Rehabil 14:602-615. CrossRef Medline

Titus DJ, Furones C, Kang Y, Atkins CM (2013a) Age-dependent alterations in cAMP signaling contribute to synaptic plasticity deficits following traumatic brain injury. Neuroscience 231:182-194. CrossRef Medline

Titus DJ, Sakurai A, Kang Y, Furones C, Jergova S, Santos R, Sick TJ, Atkins CM (2013b) Phosphodiesterase inhibition rescues chronic cognitive deficits induced by traumatic brain injury. J Neurosci 33:5216-5226. CrossRef Medline

Tsai MC, Chang CP, Peng SW, Jhuang KS, Fang YH, Lin MT, Tsao TC (2015) Therapeutic efficacy of Neuro AiD (MLC 601), a traditional Chinese medicine, in experimental traumatic brain injury. J Neuroimmune Pharmacol 10:45-54. CrossRef Medline

Urrea C, Castellanos DA, Sagen J, Tsoulfas P, Bramlett HM, Dietrich WD (2007) Widespread cellular proliferation and focal neurogenesis after traumatic brain injury in the rat. Restor Neurol Neurosci 25:65-76. Medline

Vitarbo EA, Chatzipanteli K, Kinoshita K, Truettner JS, Alonso OF, Dietrich WD (2004) Tumor necrosis factor $\alpha$ expression and protein levels after fluid percussion injury in rats: the effect of injury severity and brain temperature. Neurosurgery 55:416-424; discussion 424-425. CrossRef Medline
Wheaton P, Mathias JL, Vink R (2009) Impact of early pharmacological treatment on cognitive and behavioral outcome after traumatic brain injury in adults: a meta-analysis. J Clin Psychopharmacol 29:468-477. CrossRef Medline

Wheaton P, Mathias JL, Vink R (2011) Impact of pharmacological treatments on cognitive and behavioral outcome in the postacute stages of adult traumatic brain injury: a meta-analysis. J Clin Psychopharmacol 31:745-757. CrossRef Medline

Wilson NM, Titus DJ, Oliva AA Jr, Furones C, Atkins CM (2016) Traumatic brain injury upregulates phosphodiesterase expression in the hippocampus. Front Syst Neurosci 10:5. CrossRef Medline

Yakovlev AG, Faden AI (1994) Sequential expression of c-fos protooncogene, TNF-alpha, and dynorphin genes in spinal cord following experimental traumatic injury. Mol Chem Neuropathol 23:179-190. CrossRef Medline

Zaloshnja E, Miller T, Langlois JA, Selassie AW (2008) Prevalence of longterm disability from traumatic brain injury in the civilian population of the United States, 2005. J Head Trauma Rehabil 23:394-400. CrossRef Medline

Zhang HT, Huang Y, Masood A, Stolinski LR, Li Y, Zhang L, Dlaboga D, Jin SL, Conti M, O'Donnell JM (2008) Anxiogenic-like behavioral phenotype of mice deficient in phosphodiesterase 4B (PDE4B). Neuropsychopharmacology 33:1611-1623. CrossRef Medline 